\title{
DETERMINAÇÃO ESPECTROFOTOMÉTRICA DE BAIXAS CONCENTRAÇŌES DE ORTOFOSFATO EM ÁGUAS NATURAIS COM EMPREGO DE RESINA DE TROCA IÔNICA EM SISTEMA DE INJEÇÃO EM. FLUXO
}

\author{
LUIZ CARLOS RUIZ PESSENDA
}

Orientador: ANTONIO OCTÁVIO JACINTHO

Dissertação apresentada à Escola Superior de Agricultura “Luiz de Queiroz", da Universidade de São Paulo, para obtenção do título de Mestre em Energia: Nuclęar na Agricultura.

PIRACICABA

Estado de São Paulo - Brasil

Dezembro - 1981 
Aos meus pais,

Pedro Américo e Ruth,

pelo amor, carinho e respeito

que sempre me dedicaram,

$$
\text { OFEREC O }
$$

Aos meus irmãos,

Clãudio, José Luiz e Ana Paula,

amigos inseparāveis, 


\section{AGRADECTMENTOS}

- Ao Centro de Energia Nuclear na Agricultura (CENA), pela oportunidade o ferecida.

- Ao Dr. Henrique Bergamin Filho, pela confiança.

- Ao Dr. Virgilio Franco do Nascimento Filho e ao José Osório Bertoli, pela ajuda na parte inicial deste trabalho e pela amizade.

- Aos Professores Boaventura Freire dos Reis, Elias Ayres Guidetti Zagatto e Maria Fernanda Giné Rosias, pelo apoio em todas as etapas deste trabalho.

- Aos colegas Elisabete de Nadai Fernandes, José Roberto Ferreira, NeZson Nepomuceno e Silvana Moreira Simabuco, pela ajuda e amizade.

- Ao colega Jefferson Mortatti, pela confecção dos desenhos e pela ajuda re cebida.

- Aos técnicos de laboratório Iolanda Aparecida Rufini, Oscar Bahia Filho, Renato Eugênio Diniz, Neusa Maria Mendes Tonin, Isabel Cristina Zambeta, Valdemir Ap. Fernandes de Barros, Elaine do Carmo Batiston, Solange Silveira Amancio e Aparecida de Fátima Patreze, pela constante colaboração e amizade.

- À Comissão Nacional de Energia Nuclear (CNEN) e ao Conselho Nacional de Desenvolvimento Cientifico e Tecnológico (CNPq), pela ajuda financeira.

- Ao Dr. Paulo Leonel Libardi, pelo seu apoio na concessão da Bolsa de Estú dos do CNPq. 
- Aos Professores José Carlos de Araújo Silva e Sérgio Oliveira Moraes, pe1a força e amizade durante a realização do curso e deste trabalho.

- Às bibliotecárias Janeti L. Bombini de Moura, Rosa Maria V. B. Oliveira,

- Pedrila de Fátima Pellegrinotti e Märcia A. Leite, do CENA, pela ajuda e carinhosa atenção.

- À Srta. Alzira Ferraz e ao Sr. João Eduardo Pilotto, pelos serviços de da tilografia deste trabalho e pela amizade.

- Aos colegas Benedito Herculano Davanzo e Celso de Aguiar, responsáveis pe 1a Gráfica do CENA, pela ajuda na confecção deste trabalho.

- À Sra. Diva Athiê, pela revisão da tradu ção do resumo.

- A todos os funcionários do CENA, pela convivência amiga e prestimosa e a todas as pessoas que, de uma forma igualmente valiosa, contribuíram para a realização deste trábalho. 


\section{AGRADECIMENTO ESPECIAL}

Com palavras de estímulo e confiança, eles me ajudaram

a superar os momentos mais difíceis deste trabalho:

Dr. Antonio Octávio Jacintho, orientador e amigo,

e

Dr. Francisco José Krug, amigo e irmão. 


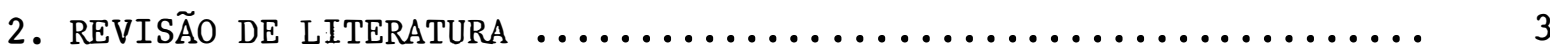

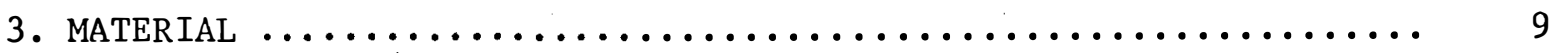

3.1. Instrumentos e Acessórios $\ldots \ldots \ldots \ldots \ldots \ldots \ldots \ldots \ldots \ldots .9 . \ldots$

3.2. Reagentes $\ldots \ldots \ldots \ldots \ldots \ldots \ldots \ldots \ldots \ldots \ldots \ldots \ldots \ldots \ldots \ldots, 10$

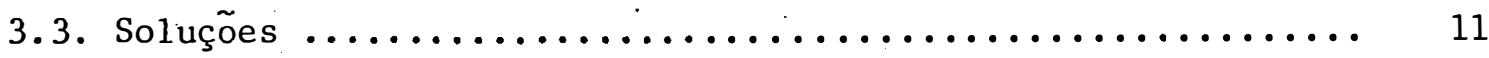

3.4. Construção das Colunas de Resina ................... 12

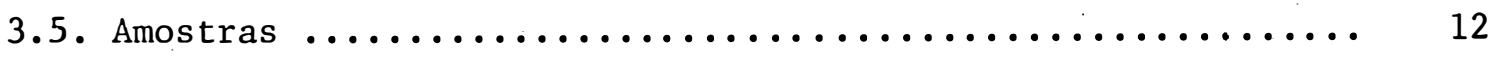

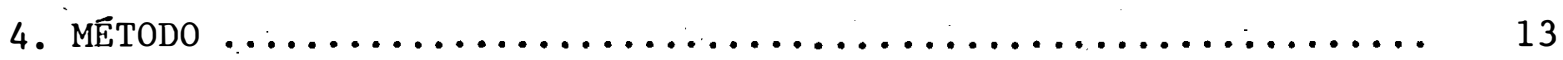

4.1. Aspectos Teóricos (Resinas de Troca Iônica) ............. 13

4.2. Estudos de Pré-Concentração e Eluição de Fosfato com Resina de Troca Iônica Acoplada a Detector Geiger-Muller (Conside-

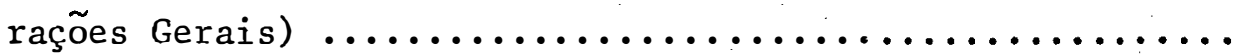

4.2.1. Tratamento Inicial e Concentração da Solução Radio ativa ............................... 19

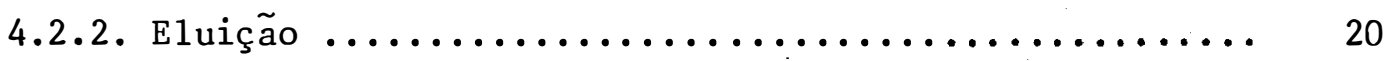

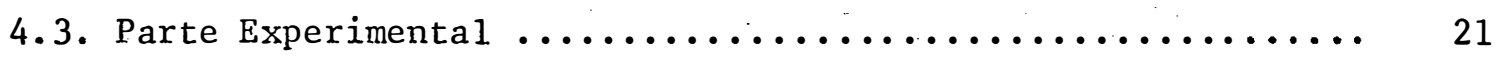

4.3.1. Influência da Intensidade do Fluxo da Amostra ...... $2 i$

4.3.2. Influência da Intensidade de Fluxo e do Tempo de

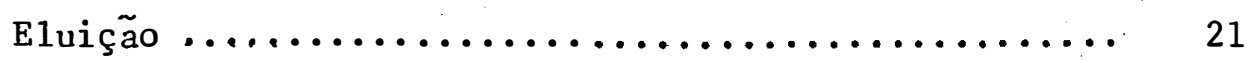

4.3.3. Relações entre as Intensidades de Fluxo de Eluição e as Concentrações do Eluente ................. 22

4.3.4. Influência dos Ions Cloreto, Nitrato e Sulfato na Eluição de Fosfato $\ldots \ldots \ldots \ldots \ldots \ldots \ldots \ldots \ldots \ldots, 22$

4.4. Características do Método Espectrofotométrico ........... 23 
4.5. Projeto do Sistema de Fluxos $\ldots \ldots \ldots \ldots \ldots \ldots \ldots \ldots \ldots \ldots . \ldots \ldots$

4.5.1. Influência da Acidez ...................... 27

4.5.2. Influência da Concentração de Molibdato .......... 27

4.5.3. Influência do Volume de Amostra Injetado .......... 27

4.5.4. Influência do Comprimento de Onda na Absorção do Composto ............................... 27

4.5.5. Influência do Cloreto Estanoso ............... 28

4.5.6. Influência do Eluente na Reação Colorimétrica de Fosfato ................................ 28

4.5.7. Influência de Alguns Ions na Retenção de Fosfato na Coluna de Resina ...................... 29

4.5.8. Efeito do Tempo de Pré-Concentração da Amostra ..... 30

4.5.9. Efeito do $\mathrm{pH}$ ou das Formas de Fosfato ........... 30

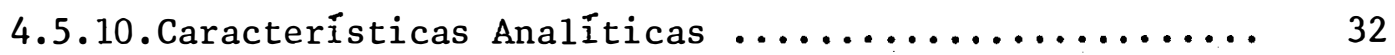

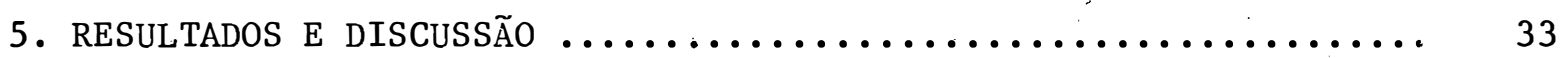

5.1. Influência da Intensidade do Fluxo da Amostra .......... 33

5.2. Influência da Intensidade de Fluxo e do Tempo de Eluição Ne cessärio

5.3. Relação Entre a Intensidade de Fluxo de Eluição e as Concen

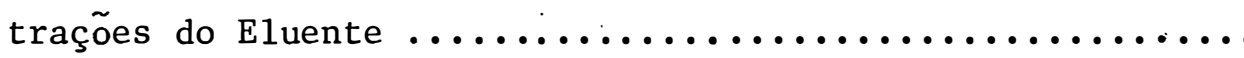

5.4. Influência dos Ions Cloreto, Nitrato e Sulfato na Elui-

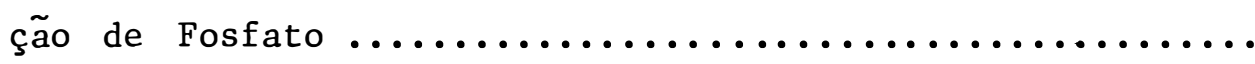

5.5. Influência da Acidez (Método Espectrofotométrico) ........ 41

5.6. Influência da Concentração de Molibdato ............. 43

5.7. Influência do Volume de Amostra Injetado ............ 43

5.8. Influência do Comprimento de Onda na Absorção do Compos

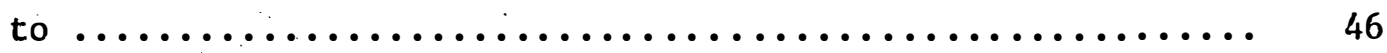

5.9. Influência do Cloreto Estanoso ................. 48 
-vii-

Pāgina

5.10. Influência do Eluente na Reação Colorimétrica de Fos-

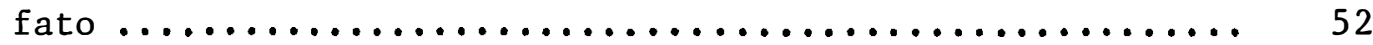

5.11. Influência de Alguns Ions na Retenção de Fosfato na Co-

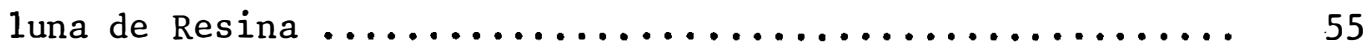

5.12. Efeito do Tempo de Pré-Concentração da Amostra ......... 58

5.13. Efeito do $\mathrm{pH}$ ou das Formas de Fosfato ................ 60

5.14. Características Analíticas ....................... 61

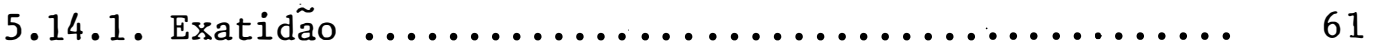

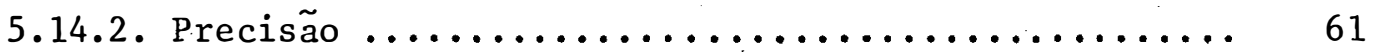

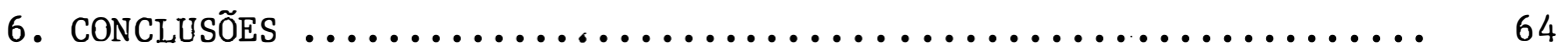

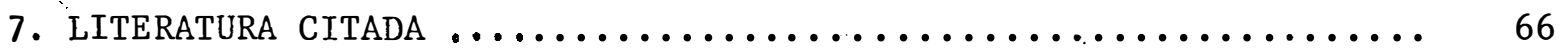


-viii-

\section{LISTA DE TABELAS}

$\underline{T a b e l a}$

Pägina

1 - Características de resinas trocadoras de ânions fortemente básicas (OHLWEILER, 1974) ..................... 14

2 - Influência dos íons $\mathrm{Cl}^{-}, \mathrm{SO}_{4}^{2-}$ e $\mathrm{NO}_{3}^{-}$na retenção de fosfato na coluna de resina $\ldots \ldots \ldots \ldots \ldots \ldots \ldots \ldots \ldots \ldots$

3 - Efeito das soluções carregadoras de amostra (eluente) na reação colorimétrica do fosfato .................. 54

4 - Teste de recuperação 


\section{LISTA DE FIGURAS}

Figura

Pägina

1 - Diagrama de um sistema de injeção em fluxo $\ldots . \ldots \ldots \ldots$.

2 - Diagrama de fluxos do sistema utilizado para o estudo de pré-concentração e eluição do fosfato em resina de tro

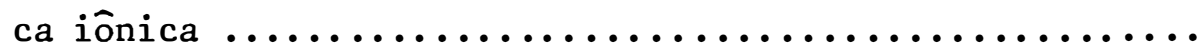

3 - Diagrama de fluxos do sistema utilizado para fins experimentais $\ldots \ldots \ldots \ldots \ldots \ldots \ldots \ldots \ldots \ldots \ldots \ldots \ldots$

4 - Diagrama de fluxos do sistema utilizado para a determina

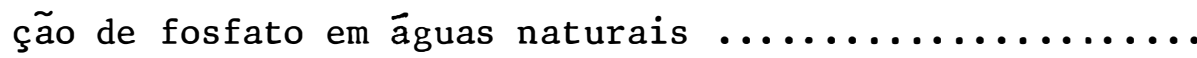

5 - Influência da intensidade de fluxo na pré-concentração de fosfato na coluna de resina

6 - Influência da intensidade do fluxo e tempo de eluição ....

7 - Relação entre as intensidades de fluxo de eluição e as

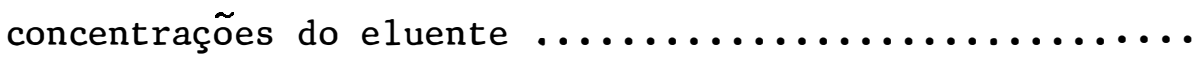

8 - Influência da acidez na reação cólorimétrica ..........

9 - Influência da concentração de molibdato ............

10 - Influência do volume de amostra injetado ...........

11 - Espectro de absorção do composto azul de molibdênio ......

12 - Efeito da concentração de cloreto estanoso no sistema 
13 - Cinética e formação de cor do azul de molibdênio ........

14 Influência do íon cloreto na retenção de fosfato na coluna de resina (forma $\mathrm{NO}_{3}^{-}$) $\ldots \ldots \ldots \ldots \ldots \ldots \ldots \ldots$

15 - Valores de absorbância de padrões de fosfato em ausência

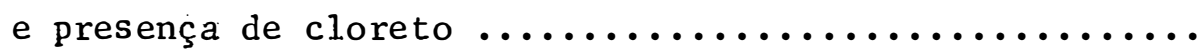

16 - Efeito do tempo de pré-concentração da amostra na colu-

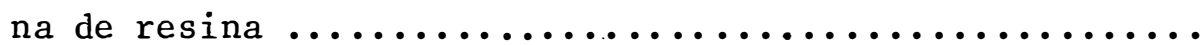

17 Resultado gráfico da determinação de fosfato em águas na turais através da pré-concentração em resina de troca iô

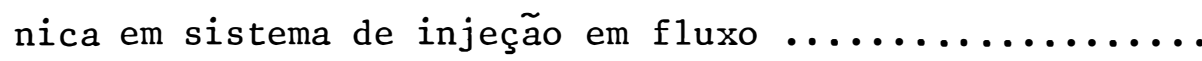


DETERMINAÇĀO ESPECTROFOTOMETRICA DE BAIXAS CONCENTRAÇŌES DE ORTOFOSFATO EM AGGUAS AHTURAIS COM EMPREGO DE RESINA DE TROCA IŌNICA

EM SISTEMA DE INJEÇÃO EM FLUXO

Luiz Carlos Ruiz Pessenda

\begin{abstract}
Antonio Octavio Jacintho
\end{abstract}
Orientador

\title{
RESUMO
}

Foram estudados vários aspectos do método do azul de molib dênio em sistema de injeção em fluxo, visando a determinação de baixas con centrações de ortofosfato em águas naturais. Resina de troca iônica foi incorporada ao sistema proposto para a pré-concentração do referido İon.

Inicialmente, no estudo de prē-concentração e eluição do fos fato na coluna de resina, utilizou-se a técnica do traçador radioativo, mar cando-se as soluções padrõ̀es com ${ }^{32} \mathrm{P}$ e fazendo-se a detecção através de um Geiger-Muller. Efeitos da intensidade dos fluxos na pré-concentração e e luição da relação entre a concentração do eluente e sua intensidade de flu xo e a ação de vários agentes eluentes foram investigados.

A seguir, foram verificados os efeitos da concentração dos 
reagentes, volume injetado de amostra, comprimento de onda e eluentes no método colorimétrico. Foram investigados também os efeitos da presença de outros íons, do $\mathrm{pH}$ ou das formas de fosfato e do tempo de pré-concentra ção.

0 sistema proposto permite a determinação de 0,005 a 0,100 ppm de fosfato em águas naturais, com uma precisão superior a $99 \%$, a uma velocidade analítica em torno de 40 determinações por hora. No teste de recuperação, a média de recuperação foi de aproximadamente $98 \%$. 


\title{
FLOW INJECTION SPECTROPHOTOMETRIC DETERMINATION OF LOW CONCENTRATIONS
} OF ORTHOPHOSPHATE IN NATURAL WATERS EMPLOYING ION EXCHANGE RESIN

Luiz Carlos Ruiz Pessenda

\author{
Antonio Octavio Jacintho \\ Adviser
}

\section{SUMMARY}

A simple and fast method for the determination of low concentrations of orthophosphate in natural waters is described. Ion exchange is incorporated into a flow injection system by using a resin column in the sample loop of a proportional injector. Effects of sample aspiration rate, sampling time, eluting agent concentration, pumping rate of the sample carrier stream and interferences, were investigated both using ${ }^{32} \mathrm{PO}_{4}^{3-}$ or ${ }^{31} \mathrm{PO}_{4}^{3-}$ with columns coupled to a Geiger-Muller detector and incorporated in a flow system with molybdenum blue colorimetry. The proposed method is characterized by good precision (r.s.d. < $1.0 \%$ ), a sampling rate of about 40 samples per hour and permits the determination of orthophosphate in the range $0.005-0.100 \mathrm{ppm}$. Standard additions of orthophosphate to natural lake water samples showed recoveries from 94.59 to $103.12 \%$. Also, an alternative flow diagram for the determination of orthophosphate in the range $0.10-2.00 \mathrm{ppm}$ is presented. 


\section{INTRODUÇÃO}

0 fósforo é um macronutriente essencial não só para a vida das plantas como dos animais e ocorre em águas naturais na forma de vārios tipos de fosfatos, os quais são comumente classificados como ortofosfato, fosfatos condensados (piro-, meta- e polifosfatos) e fosfatos orgânicos (APHA/AWWA/WPCF, 1975).

De acordo com o referido trabalho, o "ortofosfato" é a forma analisada colorimetricamente sem uma hidrólise preliminar ou digestão oxidativa da amostra e que a utilização de uma membrana de 0,45 $\mu \mathrm{m}$ e uma hidrólise ācida são empregadas para converter fosfatos condensados em orto fosfato filtrável. No entanto, as frações que são convertidas para ortofosfato somente por destruição oxidativa da matéria orgânica são considera das orgânicas ou fosfato "organicamente preso".

Tais formas, mesmo estando presentes em pequenas quantidades, têm considerável significado na biologia da āgua.

TAYLOR (1958) demonstrou que fosfato conjuntamente com sỉli ca estão intimamente relacionados com a presença e desenvolvimento do fito 
plancton. Segundo APHA/AWWA/WPCF (1975), o fosfato é essencial para o cres cimento e produção de macro e microorganismos aquáticos.

Muito embora vários métodos químicos manuais para a determinação de fosfato tenham sido desenvolvidos, na maioria deles a sensibilidade conseguida não tem sido suficiente para determinar as baixas concentrações do fosfato das águas naturais, alēm de serem lentos e trabalhosos.

Desse modo, o presente trabalho teve como objetivo o desenvolvimento de uma metodologia automática que possibilitasse a determinação das baixas concentrações de fosfato em āguas naturais utilizando a pré-concentração do referido ín através do emprego de resina de troca iônica, para posterior determinação do fosfato pelo método do azul de molibdênio atra vēs do sistema de injeção em fluxo, visando, principalmente, simplicidade operacional, velocidade analítica e adequadas condições de precisão e e xatidão.

0 uso de ${ }^{32} \mathrm{P}$ se fez necessārio para o estudo de prē-concentração e, principalmente, eluição do fosfato em resina de troca iônica, ten do em vista o estabelecimento das melhores condições analíticas para o méto do colorimétrico. 


\section{REVISĀO DE LITERATURA}

Na presente revisão, procurou-se dar ênfase aos sistemas ana líticos que empregam a injeção em fluxo, a técnicas de pré-concentração e aos métodos manuais e automáticos de determinação de fosfato em águas naturais.

Dentre os sistemas automāticos de anālise, destaca-se, por suas características de precisão, exatidão, velocidade analítica e consumo de amostras e reagentes, o que emprega injeção em fluxo, FIA*, proposto em 1975 (RUZICKA e HANSEN, 1975). No Brasil, este sistema foi introduzido por RUZICKA e STEWART (1975), utilizando injeção de amostras líqui das em um fluido carregador não segmentado por ar. Apōs a injeção, é estabelecida uma zona de amostra muito bem definida: (RUZICKA e HANSEN, 1975; REIS et alii, 1981), a qual sofre um processo contínuo de dispersão pelo fluido carregador, à medida em que é transportada pela mesma, em direção à unidade de detecção. No percurso analítico, a zona de amostra pode receber reagentes bem como participar de diversos processos, tais como diālise (HANSEN e RUZICKA, 1976), extração por solventes (MEDEIROS, 1979; MORTATTI, 1981), pré-concentração por resina iônicas (BERGAMIN et alii, 
1980), etc. O sistema de detecção mede a espécie de interesse produzida, e geralmente um registrador coleta um sinal transiente, em forma de pico, cuja altura ou à̉rea (WOLF e STEWART, 1979) é proporcional à concentração do elemento a analisar. Espectrofotometria, potenciometria e espectrometria de absorção e emissão atômica têm sido empregadas rotineiramente em FIA, conforme indicam recentes revisões (RUZICKA e HANSEN, 1981; RANGER, 1981).

Determinações espectrofotométricas de fosfato em sistemas FIA têm sido desenvolvidas para a anālise de plantas. (RUZICKA e STEWART, 1975), fertilizantes (HANSEN et alii, 1977), soro de sangue (HANSEN e RUZICKA, 1976), etc.

Uma vez que a concentração de fósforo em águas naturais situa-se geralmente entre 1 e $50 \mathrm{ppb}$ de $\mathrm{P}$ ( $\mu \mathrm{g} / 1$ ) (JONES e SPENCER, 1963; HENRIKSEN, 1965; TAYLOR, 1958; STEVENS, 1963), e os métodos já desenvolvidos em FIA não apresentavam sensibilidade suficiente para a determinação de tais teores, uma técnica de pré-concentração da amostra poderia ser utilizada. Um dos processos de pré-concentração do material a ser utilizado, empregado em procedimentos manuais, é a extração por solventes orgânicos.

HESLOP e PEARSON (1967) utilizaram vārios solventes orgânicos (n-butanol, isobutanol, ciclohexanol, etc.) para concentração e separa ção do fósfororo em presença de arsênio. Fósforo pode ser concentrado e separado do silício, arsênio e germânio por processo de extração com acetato de isobutila, mantendo o pH entre 0,8 e 1,0 (PAUL, 1966).

Ālcool isoamílico é utilizado na determinação de fósforo em 
ligas metālicas, onde o composto ácido molibdofosfórico amarelo è extraído e reduzido, em seguida, para azul (PAKALNS, 1970).

Outros solventes têm sido empregados na determinação do fósfọ ro em vārias matrizes. Em ligas de aço o isobutanol (THEABSTON e BANDI, 1966), em materiais biológicos o àlcool n-butílico (GING, 1956), e em metais, tais como o alumínio, cobre e níquel, o acetato de isoamila e acetato de iso butila, respectivamente. Em todos esses métodos a determinação é lenta e trabalhosa.

Em FIA, outros métodos foram desenvolvidos empregando a técni ca de extração por solvente. Determinação de cafeína em ācido acetilsalicílico (KARLBERG e THELANDER, 1978), molibdênio, em extratos vegetais (MEDEIROS, 1979), traços de cádmio e chumbo em cerâmica vitrificada (KLINGHOFFER et alii, 1979) e chumbio em àguas naturais e extratos vegetais (MORTATTI, 1981). Esta técnica apresenta alguns inconvenientes. O solvente orgânico, que è bombeado através do sistema de fluxo, necessita de tubulações especiais, que têm uma vida útil bastante pequena. E de necessidade prātica, para o estudo da razão fase-aquosa-orgânica, uma câmara especial de separação e extração, a qual é de difícil obtenção ou construção. De uma forma geral, a montagem de um sistema de extração por solventes orgânicos em FIA, para anālises de rotina, è bastante trabalhosa.

Assim sendo, uma outra técnica de pré-concentração da amostra, economicamente viāvel, de operação simples e que não necessita de acessórios específicos para sua utilização, é aquela baseada no emprego de resinas de troca iônica. Esses materiais vêm sendo amplamente empregados nos processos de separação e pré-concentração de uma grande variedade de íons 
(FLORENCE, 1975; KINGSTON, 1978; YAMAGAMI, 1980). 0 uso de resina de troca iônica para a anālise de fosfato não é extenso. Nos trabalhos revisados, nota-se que o objetivo principal dos autores é a separação das diversas for mas existentes.

Segundo GRANDE e BEUKENKAMP (1956), o conhecimento da distribuição dos polímeros fosfatados é de considerável interesse na indūstria de detergentes sintéticos, sob o ponto de vista de estabilidade do fosfato, pureza do material bruto e análise do produto final. Os autores concentraram e separaram cinco formas de fosfato presentes neste material com resina aniônica Dowex 1-X8 (100-200 mesh). Na eluição, utilizaram uma solução de $\mathrm{KCl}$ - 1M, em $\mathrm{pH}^{-5,0}$. A determinação das diferentes formas (como ortofosfato) era feita de maneira semelhante a BARTON (1948). A mesma técnica tem sido empregada por diversos autores para a pré-concentração e separação de formas de fosfato em detergentes sintéticos (POLLARD et alZii, 1962; SPANGLER et alii, 1950; KOLLOFF, 1959).

LINDENBAUM et alii (1954) fizeram a separação de uma mistura de 5 formas de fosfato, utilizando a resina Dowex 1-X8 e várias concentrações do agente eluidor (KC1) em $\mathrm{pH}$ 5,0 e 7,0, onde descreveram que o pro cesso é mais satisfatório em pH 5,0. PETERS e RIEMAN III (1956) utilizaram a mesma técnica em $\mathrm{pH}$ 5,0 e 9,0, sem entretanto notar a diferença na separação. Em ambos os casos, as frações coletadas eram hidrolizadas com ācido nítrico para que todas as formas presentes passassem para ortofosfato, com posterior determinação colorimétrica através do método do vanadato de amônio (amare1o). 
BLANCHAR e RIEGO (1975). Amostras contendo desde 1 hg até $100 \mu \mathrm{g}$ por 1itro de solução foram passadas através de uma coluna de resina Dowex 1 - X8 (100-200 mesh) e eluídas com NaC1-1M, em pH 5,0. Após, o fosfato contido na solução de $\mathrm{NaCl}$ reagiu com molibdato de amônio, foi extraído em isobu tanol, reduzido com cloreto estanoso e a leitura feita a $660 \mathrm{~nm}$. Interferentes estiveram ausentes, uma vez que o composto fosfomolibdato foi extra ído em isobutanol antes da redução com cloreto estanoso. Com a técnica empregada, os autores conseguiram uma recuperação de $97 \%$.

APHA/AWWA/WPCF (1975) recomendam para determinação de fosfạ to em águas naturais o método do azul de molibdênio, devido à sua maior sensibilidade. De acordo com os autores, o mínimo detectável no método do vanadato de amônio (amare1o) é de $200 \mathrm{ppb}$ de P. Para o método do azul, em pregando cloreto estanoso e uma extração com uma mistura benzeno-isobutanol, chega-se a $3 \mathrm{ppb}$. o ácido ascórbico também é descrito como redutor, sendo que, nestas condições, a concentração mínima detectáve1 è de 10 ppb. o método do amarelo foi utilizado por ABBOT et alii (1963) com a mesma finalidade.

SHEN e DYROFF (1964) estudaram a determinação de fósforo em águas em presença de sílica, tendo o ácido 1-amino, 2-nafto1, 4-sulfôni co como redutor. Demonstraram que o emprego de um meio suficientemente àcido $\left(>0,7 \mathrm{~N} \mathrm{H}_{2} \mathrm{SO}_{4}\right)$ eliminava a interferência de silício.

Com a demanda de um nümero cada vez maior de análises, surgiram os métodos automáticos que utilizamo auto-analisador da Technicon.

HENRIKSEN (1965) chegou a determinar 1 ppb de $\mathrm{P}$ em águas, a 
plicando a técnica de extração por solventes (isobutanol) e usando cloreto estanoso $(0,02 \%$ em isobutano1) como redutor. Foi conseguida uma velocidade de 12 determinações por hora.

0 método proposto pela TECHNICON (1973) permitiu uma veloci dade analítica de 50 determinações por hora, empregando ácido ascórbico co mo redutor e um limite de sensibilidade de 0,02 ppm $\mathrm{P}$ foi atingido. Vários íons aparecem como interferentes em tal método (arsênio, vanádio, titânio, zircônio e germânio).

De acordo com TYLER e BILES (1970), todas as formas inorgânicas de fósforo podem ser convertidas para ortofosfato após digestão ācida da amostra a 300 a $340^{\circ} \mathrm{C}$ e determinadas pelo método do azul. A concentração mínima detectável foi de 0,05 ppm de $\mathrm{P}$, a uma velocidade analítica de 10 determinações por hora. 


\section{MATERIAL}

\subsection{Instrumentos e Acessōrios}

Colorímetro Corning, modelo 254, equipado com uma cubeta de fluxo Helma, modelo 178-0S passo ótico $10 \mathrm{~mm}$, volume $80 \mu 1$.

Registrador Radiometer, modelo REC 61, com unidade de alta sensibilidade REA 112.

Bomba Peristāltica Technicon, modelo AA II.

Bomba Peristāltica ISMATEC, modelo iP 12.

Injetores de Amostra, do tipo proporcional, construídos em a crílico, conforme descrito por BERGAMIN Fo et alii (1978).

Junções de acrílico para confluência.

Tubos de Tygon, de diferentes diâmetros internos, para obtenção de värias intensidades de fluxos.

Tubos de polietilenocom diâmetro interno de $0,08 \mathrm{~cm}$, para a 
construção do sistema de fluxo.

Vidraria de uso rotineiro em laboratórios de química analíti

ca.

Contador (Scaler) Nuclear Chicago, modelo Estudent no 1870.

Tubo Geiger-Muller, da BAIRD ATOMIC, modelo 908-108, com diạ metro de $2,7 \mathrm{~cm}$; janela de mica com $1,4 \mathrm{mg} / \mathrm{cm}^{2}$ de densidade superficial.

"Timer" ${ }^{*}$ eletrônico diretamente acoplado ao contador.

Tubos de polietileno de 0,20 cm de diâmetro interno.

Resina Dowex 1-X8 aniônica forte $\left(\mathrm{C}^{-}\right), 100-200$ mesh, com ca pacidade de $3,5 \mathrm{meq} / \mathrm{g}$.

\subsection{Reagentes}

Todos os reagentes utilizados foram pro-análise, e todas as soluções foram preparadas com água destilada desmineralizada.

- cloreto de sódio

- molibdato de amônio

- cloreto estanoso

- nitrato de sódio

- nitrato de amônio

- ācido sulfúrico

(*) "Timer" - controlador automático de tempo. 
- ācido clorídrico

- sulfato de amônio

- ācido ascōrbico

- fosfato diácido de potássio

\subsection{Soluções}

Solução de cloreto de sódio - 1,00; 0,50 e 0,25N.

Solução de nitrato de amônio - 1,00; 0,50 e 0,25N.

Solução de nitrato de sódio - 1,00; 0,50 e 0,25N.

Solução de sulfato de amônio - 1,00M.

Solução de cloreto estanoso $10 \%$ e $1,00 \mathrm{~N}$ em HC1-dissolveram se $10 \mathrm{~g}$ de cloreto estanoso em $8,5 \mathrm{ml}$ de $\mathrm{HCl}$ concentrado. A seguir, completou-se o volume a $100 \mathrm{ml}$ com água destilada. A partir deste estoque foi preparada diariamente uma solução de trabalho de concentração igual a 0,050 $\%$ em $\mathrm{HCl} 5 \mathrm{mN}$.

Soluções aquosas de molibdato de amônio - $(0,5 \% ; 1,0 \% ; 1,5 \%$ e $2,0 \% \mathrm{~m} / \mathrm{v})$.

Soluções aquosas de ácido sulfúrico - (3N, 4N, 5N, 6N e 7N). Solução estoque $100 \mathrm{ppm}$ de $\mathrm{PO}_{4}^{3-}\left(\mathrm{KH}_{2} \mathrm{PO}_{4}\right)$ - pesou-se $0,1433 \mathrm{~g}$ deste sal, previamente seco, e dissolveu-se em $1000 \mathrm{~m} 1$ de água destilada. A partir deste estoque, foram preparadas soluções de trabalho contendo des de 0,000 a 2,000 ppm de $\mathrm{PO}_{4}^{3-}$.

Solução estoque $1000 \mathrm{ppm} \mathrm{So}_{4}^{2-}$ - dissolveram-se $1,376 \mathrm{~g}$ de $\left(\mathrm{NH}_{4}\right)_{2} \mathrm{SO}_{4}$, previamente seco, em $1000 \mathrm{ml}$ de água destilada.

Solução estoque $1000 \mathrm{ppm} \mathrm{NO}_{3}^{-}$- dissolveram-se $1,517 \mathrm{~g}$ de $\mathrm{NaNO}_{3}$, previamente seco, em $250 \mathrm{ml}$ de água destilada. 
Solução 1000 ppm de C1 - dissolveu-se 0,8242 g de $\mathrm{NaCl}$, previamente seco, em $500 \mathrm{ml}$ de àgua destilada.

A partir da solução estoque de fosfato, foram preparados padrões desde 0,0 a 0,1 ppm, contendo separadamente $100 \mathrm{ppm}$ de sulfato, 100 ppm de nitrato e 300, 100 e 50 ppm de cloreto, respectivamente.

Solução ācido áscórbico $10 \% \mathrm{~m} / \mathrm{v}$.

Procedência e atividade inicial do material radioativo:Ins tituto de Pesquisas Energéticas e Nucleares. Atividade entre 1,0 mCi e 2,5 mCi, livre de carregador, forma $\mathrm{Na}_{2} \mathrm{H}^{32} \mathrm{PO}_{4}$

Soluções radioativas de fósforo - com atividade de $1,0 \mathrm{nCi} /$ $\mathrm{m} 1$ a $10 \mathrm{nCi} / \mathrm{ml}$, contendo carregador $1 \mathrm{ppm} \mathrm{P0}_{4}^{3-}$.

\subsection{Construção das Colunas de Resina}

Pesaram-se $115 \mathrm{mg}$ de resina Dowex 1-X8 e colocaram-se em um becker, com aproximadamente $50 \mathrm{ml}$ de água destilada. A seguir, transferiu-se esta quantidade (com auxílio de uma seringa) para a coluna de polietileno de 3,5 cm de comprimento e diâmetro interno de 0,20 cm. Para se evitar uma perda de resina durante a análise, vedou-se a coluna em ambas as extremidades com lã de vidro. Nas colunas de comprimentos 4,5, 5,5 e $6,5 \mathrm{~cm}$, utilizaram-se 147,180 e $213 \mathrm{mg}$ de resina, respectivamente.

\subsection{Amostras}

As amostras de āguas naturais, obtidas junto à Universidade Federal de São Carlos, eram provenientes de diversas represas do Estado de São Paulo. Imediatamente após a coleta (APHA/AWWA/WPCF, 1975), estas amostras foram filtradas através de uma membrana de 0,45 $\mu \mathrm{m}$ e preservadas a $-10^{\circ} \mathrm{C}$ em frascos de vidro. 


\section{METODO}

\subsection{Aspectos Teóricos (Resinas de Troca Iônica)}

Resinas trocadoras de íons podem ser definidas como materiais sintēticos que contêm uma malha ou matriz, à qual são fixadas por adsorção cargas positivas ou negativas. Desta forma, para preservar a neutralidade elétrica, estes sólidos devem conter outros íons móveis ou removíveis, de carga oposta. Se a malha possuir uma carga negativa, os íons removíveis de verão ser carregados positivamente, e estes materiais são trocadores catiônicos. Por outro lado, para uma malha de carga positiva, os íons removíveis terão carga negativa e estes materiais serão trocadores aniônicos (KRAUS, 1957; OHLWEILER, 1974).

No presente trabalho, a atenção foi voltada para as resinas a niônicas. Tais resinas são divididas em dois grupos: forte e fracamente bāsicas.

Segundo SAMUELSON (1963), as resinas do tipo fortemente bási cas são muito mais usadas em química analítica do que as fracamente básicas. o caräter fortemente básico é devido à presença do grupo amônio quaternārio 
$-\mathrm{R}\left(\mathrm{NH}_{3}\right)^{+}$(SAMUELSON, 1963; OHLWEILER, 1974; DILTS, 1974).

Estes mesmos autores citam que estas resinas podem ser usadas para trabalhos de troca iônica ou cromatográficos em meio ácido, neutro ou alcalino. Pertencem a esta categoria os produtos Amberlite IRA-400, Amberlite GG-400, Amberlite IRA-401, Dowex 1 e 2, que são vendidas na forma $\mathrm{C1}^{-}$. A Tabela 1 mostra as características de resinas trocadoras de ânions fortemente básicas.

Tabela 1 - Caracterīsticas de resinas trocadoras de ânions fortemente bās cas (OHLWEILER, 1974).

\begin{tabular}{|c|c|c|c|c|c|}
\hline \multirow{2}{*}{$\begin{array}{c}\text { Nome } \\
\text { Comercial }\end{array}$} & \multirow{2}{*}{$\begin{array}{c}\text { Grupo } \\
\text { Funcional }\end{array}$} & \multirow{2}{*}{$\begin{array}{l}\text { Forma } \\
\text { Iônica }\end{array}$} & \multicolumn{2}{|c|}{$\begin{array}{c}\text { Capacidade Total } \\
\text { de Troca }\end{array}$} & \multirow{2}{*}{$\begin{array}{c}\text { Faixa } \\
\mathrm{pH} \\
\text { Efetiva }\end{array}$} \\
\hline & & & Meq/ml & $\mathrm{Meq} / \mathrm{g}$ & \\
\hline $\begin{array}{l}\text { Amberlite } \\
\text { IRA-400 }\end{array}$ & $-\mathrm{N} \mathrm{Me}_{3}+$ & $\mathrm{C} 1^{-}$ & 1,2 & 3,3 & $0-12$ \\
\hline $\begin{array}{l}\text { Amberlite } \\
\text { GG-400 }\end{array}$ & $-\mathrm{N} \mathrm{Me}_{3}+$ & $\mathrm{C} 1^{-}$ & 1,2 & 3,3 & $0-12$ \\
\hline $\begin{array}{l}\text { Amberlite } \\
\text { IRA-401 }\end{array}$ & $-\mathrm{N} \mathrm{Me}_{3}+$ & $\mathrm{C} 1^{-}$ & 0,8 & 3,4 & $0-12$ \\
\hline Dowex 1 & $-\mathrm{N} \mathrm{Me}{ }_{3}^{+}$ & $\mathrm{C} 1^{-}$ & 1,33 & 3,5 & $0-14$ \\
\hline Dowex 2 & $-\mathrm{N} \mathrm{Me}_{2}\left(\mathrm{C}_{2} \mathrm{H}_{4} \mathrm{OH}\right)+$ & $\mathrm{Cl}^{-}$ & 1,33 & 3,5 & $0-14$ \\
\hline
\end{tabular}

Uma vez que as reações de troca iônica são reversíveis, a elas se aplica a lei da ação das massas (DILTS, 1974; OHLWEILER, 1974; SAMUELSON, 1963). 
Para o caso específico de reação de troca entre os íons fosfato e cloreto, tem-se, segundo SPANGLER et alii (1950) e KOLLOFF (1959), as seguintes equações:

$$
\begin{aligned}
& \mathrm{R}-\mathrm{C} 1+\mathrm{H}_{2} \mathrm{PO}_{4}^{-} \rightleftarrows \mathrm{R}-\mathrm{H}_{2} \mathrm{PO}_{4}+\mathrm{Cl}^{-} \\
& 2 \mathrm{R}-\mathrm{C} 1+\mathrm{HPO}_{4}^{2-} \rightleftarrows \mathrm{R}_{2}-\mathrm{HPO}_{4}+2 \mathrm{Cl}^{-} \\
& 3 \mathrm{R}-\mathrm{C} 1+\mathrm{PO}_{4}^{3-} \rightleftarrows \mathrm{R}_{3}-\mathrm{PO}_{4}+3 \mathrm{C}^{-}
\end{aligned}
$$

Para a equação (1); a constante de equilíbrio $\mathrm{K}$ ou coeficien te de seletividade é dado por

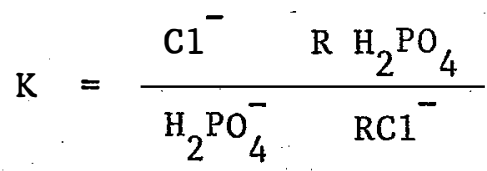

e deve-se ressaltar que esta mesma lei se aplica às equações (2) e (3).

Como cita OHLWEILER (1974), o coeficiente de seletividade so fre grande variação com a composição da resina. Não obstante, é possível dispor uma série de íons na ordem de seus coeficientes de seletividade crescentes para uma dada resina. A ordem de seletividade de ânions univalentes com :relação a Dowex 1 é a seguinte (OHLWEILER, 1974):

$\mathrm{OH}^{-}=\mathrm{F}^{-}<\mathrm{C}_{2} \mathrm{H}_{3} \mathrm{O}_{2}^{-}<\mathrm{H}_{2} \mathrm{PO}_{4}^{-}<\mathrm{HCO}_{3}^{-}<\mathrm{Cl}^{-}<\mathrm{NO}_{2}^{-}<\mathrm{HSO}_{3}^{-}<\mathrm{CN}^{-}<\mathrm{Br}^{-}<\mathrm{NO}_{3}^{-}<\mathrm{HSO}_{4}^{-}<\mathrm{I}^{-}$

Quanto à estabilidade, do ponto de vista analítico, as resinas aniônicas são bastante estáveis quando se trabalha à temperatura ambi ente (SAMUELSON, 1963). 


\subsection{Estudos de Pré-Concentração e Eluição de Fosfato com Resina de Tro-} ca Iônica Acoplada a Detector Geiger-Muller (Considerações Gerais)

Um sistema de anālise por injeção em fluxo, de uma forma geral, pode ser representado esquematicamente como na Figura 1.

Para o estudo de prē-concentração e eluição do fosfato, subs tituir-se-ia o"loop" * de amostra A por uma coluna de resina e o carregador $\mathrm{C}_{\mathrm{A}}$ da amostra pelo agente eluente. Desde que, para a anālise colorimétrica de um composto químico qualquer, necessita-se conhecer a cinética de sua reação, e esse parâmetro, em sistema FIA, é controlado principalmente pela intensidade de fluxo $\phi_{1}$ e bobina de reação $B_{R}$, a escolha do melhor fluxo de eluição neste sistema seria bastante trabalhosa. Inicialmente, para cada fluxo carregador de amostra testado (eluente) ter-se-ia uma cinética de rea ção diferente, caso fosse fixada uma bobina da reação $B_{R}$. Por outro lado, aumentando-se a bobina de reação $B_{R}$, diferentes dispersões da amostra injetada seriam obtidas, uma vez que tal dispersão é função do comprimento de linha utilizado $\left(B_{R}\right)$. Verifica-se, portanto, que para cada vazão seriam possíveis diferentes configurações analíticas.

Consequentemente, as concentrações de reagentes teriam que ser estudadas para cada uma delas. Assim sendo, um sistema analíticomais simples foi elaborado (Figura 2). Marcaram-se as soluções aquosas com ${ }^{32} \mathrm{P}$, onde este radioisótopo serviria como substituto dos reagentes usados na co1orimetria. A detecção foi feita através de um Geiger-Muller e o poste rior estudo de eluição foi realizado sem nenhum dos problemas citados acima.

* "loop": volume de amostra injetada. 


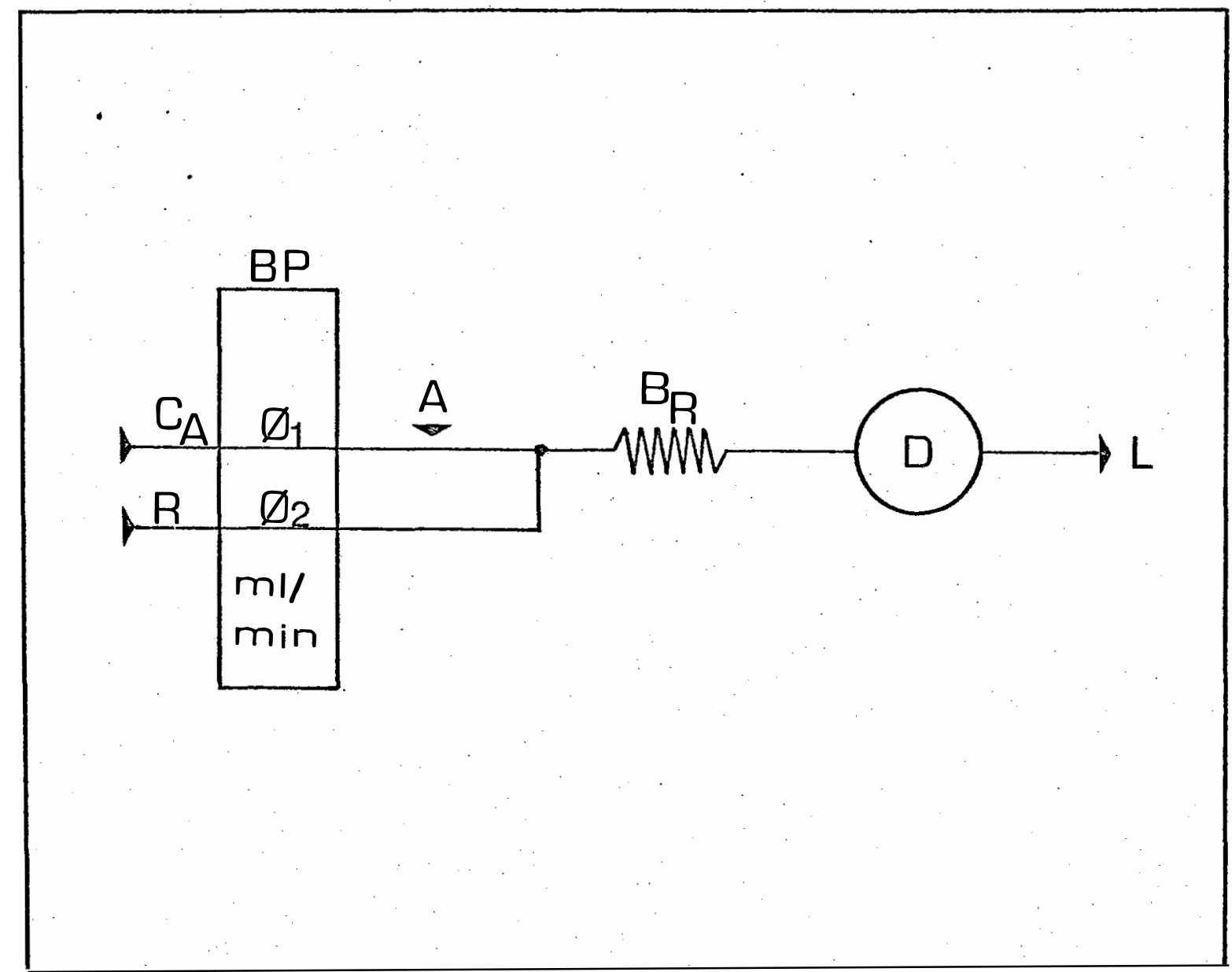

FIGURA 1 - Diagrama de um sistema de injeção em fluxo. $\mathrm{BP}=$ bomba peristāltica

$A=$ "loop" de amostra a ser injetado no sistema

$\mathrm{C}_{\mathrm{A}}=$ seu carregador

$\phi_{1}=$ sua vazão

$\mathrm{R}=$ reagente da espécie de interesse

$\phi_{2}=$ sua vazão

$\mathrm{B}_{\mathrm{R}}=$ bobina de mistura e reação

$\mathrm{D}=$ detector

$\mathrm{L}$ = saída para o descarte

(as flechas indicam o sentido do fluxo) 


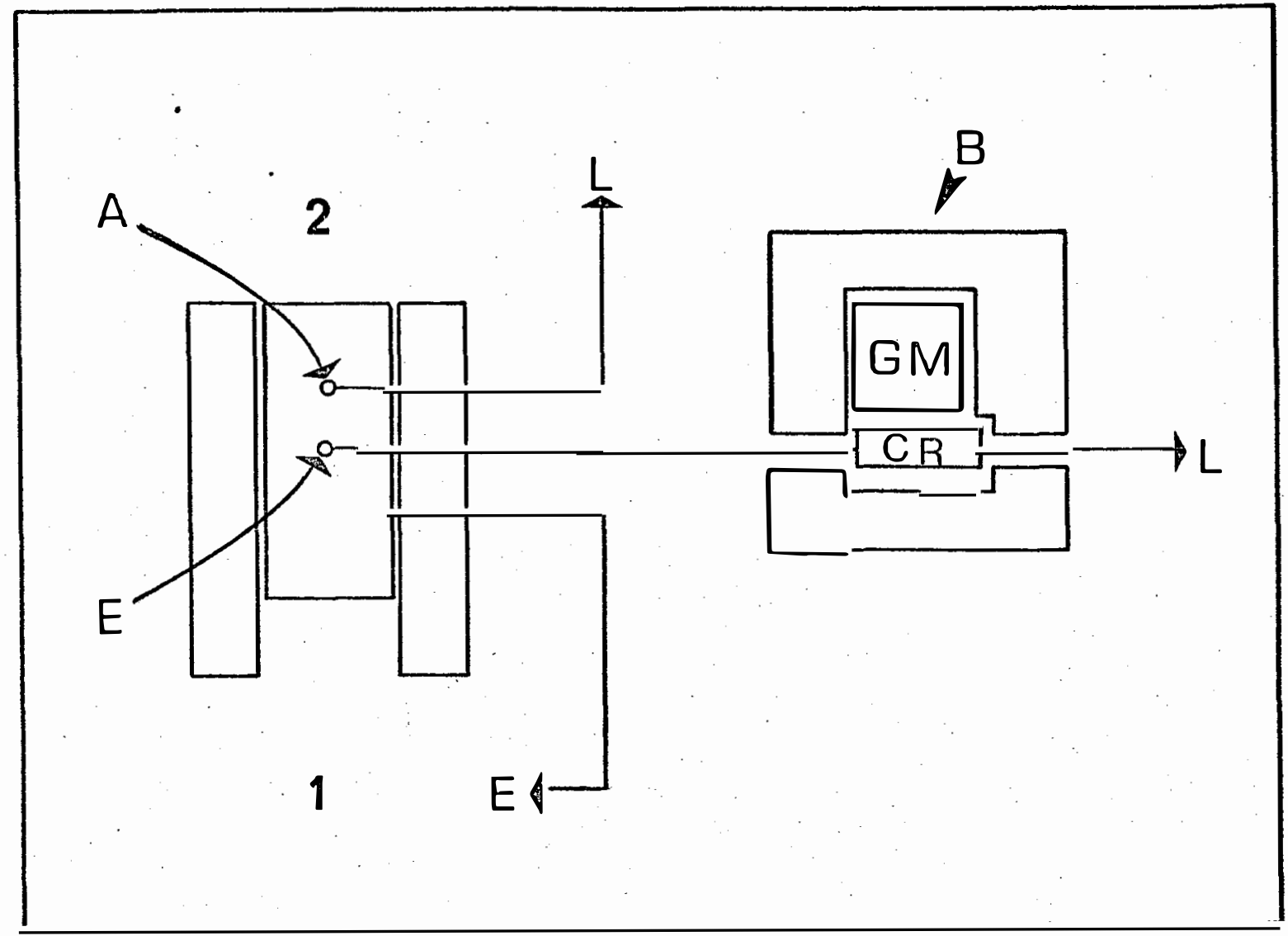

FIGURA 2 - Diagrama do sistema utilizado para o estudo de pré-concentração e eluição do fosfato marcado com ${ }^{32} \mathrm{P}$ em resina de troca iônica. $\mathrm{A}=$ amostra de fosfato marcado $\operatorname{com}{ }^{32} \mathrm{P}$

$\mathrm{E}=$ eluente $-\mathrm{NaCl}$

$\mathrm{GM}=$ detector Geiger-Muller

$\mathrm{C}_{\mathrm{R}}=$ coluna de resina

$B=$ blindagem

$\mathrm{L}$ = saída para o descarte

1 = posição de injeção da amostra

2 = posição de eluição da amostra (na figura) 


\subsubsection{Tratamento Inicial e Concentração da Solução Radioativa}

Montou-se o sistema segundo a Figura 2; a bomba peristáltica de velocidade variável impulsiona as soluções radioativas e de eluição através do sistema atē o injetor.

0 injetor possui duas posições de comutação: injeção da aamostra (1) e eluição do fosfato (2).

Na posição 2 tem-se a situação de eluição utilizada no início do experimento, onde a coluna de resina é tratada com o agente eluidor durante 5 minutos. Findo esse período, o tubo de polietileno do carrega dor da amostra (água destilada) foi transferido para o recipiente que contém a solução radioativa. Para certificar-se de que todo o tubo, desde o seu início até o injetor, estava completamente cheio com a solução radioativa, deixou-se entrar uma bolha de ar no sistema, onde o excesso de amos tra foi descartado para o lixo. Desligou-se a bomba peristáltica e comutou-se o injetor para a posição 1 , que é a posição de injeção da amostra, ou de prē-concentração.

Em seguida, ligou-se a bomba peristáltica e o conjunto "scaler-timer", simultaneamente. Durante um tempo previamente escolhido, a solução radioativa foi bombeada, passando na coluna, e o excesso descảrtado. A seguir, a bomba peristáltica foi desligada, interrompendo, desta forma a entrada da solução na coluna de resina. Por um tempo conveniente, iniciou-se a deteç̧ão do material radioativo acumulado na resina. Para a detecção e controle do tempo de concentração da solução na coluna de resi na, utilizou-se um Geiger-Muller com voltagem de operação de $900 \mathrm{~V}$, acopla do a um sistema "scaler" com "timer". 
E importante frisar que a coluna de resina foi colocada, através de um suporte metálico, à menor distância possível da janela do Geí ger-Muller. Procurou-se manter a parte anterior da coluna de resina (entrada da amostra) coincidente com a borda da janela do Geiger-Muller, visto que testes preliminares indicaram ser esta geometria a que apresentava maior eficiência de detecção.

\subsubsection{Eluição}

Para se iniciar a eluição, com a bomba peristáltica desligą da, mudou-se o tubo da solução radioativa para água destilada, evitando-se desta forma uma possível adsorção do fosfato nas paredes do tubo de polietileno.

Em seguida, ajustou-se a velocidade da bomba peristáltica e a posição do injetor e iniciou-se a passagem do eluente pela coluna durante um tempo determinado. Para verificar a quantidade do material radioativo que ficou adsorvido na resina, procedeu-se à leitura das contagens. Quando o número de contagens se aproximava da radiação de fundo ("back ground"), as leituras eram feitas durante 10 minutos.

Deve-se ressaltar que, durante o processo de concentração o eluente continuou sendo bombeado, mas retornando ao seu frasco de origem, permitindo, assim, uma economia de reagente. 


\subsection{Parte Experimental}

\subsubsection{Influência da Intensidade do Fluxo da Amostra}

A influência da intensidade do fluxo da amostra foi verifica da utilizando-se uma solução contendo aproximadamente $2,7 \mathrm{nCi} / \mathrm{ml}$, com 1,0 ppm de fosfato como carregador. O sistema foi o proposto na Figura 2 e o pro cedimento idêntico ao descrito nos ítens 4.2.1 e 4.2.2.

As vazões utilizadas foram de $1,2,5$ e $10 \mathrm{ml} / \mathrm{min}$ e os tem pos de pré-concentração da amostra de 10, 5, 2 e 1 min, respectivamente. A eluição foi feita com uma solução $1 \mathrm{~N}$ em cloreto de sódio com pH em torno de 5,0 durante 180 segundos

\subsubsection{Influência da Intensidade de Fluxo e do Tempo de Eluição Ne- cessārio}

Para o estudo do fluxo e do tempo necessário para eluir o ma terial radioativo da coluna, utilizou-se o sistema da Figura 2, com uma vazão de $10 \mathrm{ml} / \mathrm{min}$, durante 1 minuto e uma amostra com atividade aproximada de $6,7 \mathrm{nCi} / \mathrm{ml}$.

As vazões de eluição varıaram desde 1 até $10 \mathrm{ml} . \mathrm{min}^{-1}(1,2$, $4,6,8,10)$ e os tempos foram de 15 atē 180 segundos $(15,30,60,90$, 120, 150 e 180). O procedimento para a pré-concentração da solução radioativa e sua eluição nos respectivos tempos foi idêntico ao item 4.3.1. 
4.3.3. Relação entre as Intensidades de Fluxo de Eluição e as Concentrações do Eluente

A influência da vazão entre os fluxos e as concentrações na eluição do material radioativo da coluna foi verificada utilizando-se uma solução contendo aproximadamente $5,3 \mathrm{nCi} / \mathrm{ml}$, com $1 \mathrm{ppm}$ de fosfato como carregador.

Foram utilizados quatro fluxos de eluição: 1, 2, 5 e:10 ml/ min. Para cada fluxo, variaram-se as concentrações do eluente de maneira que a mesma quantidade passasse através da coluna de resina na unidade de tempo. As concentrações foram de $1,0,0,5,0,2$ e $0,1 \mathrm{~N}$ de $\mathrm{NaCl}$, respectivamente.

A intensidade do fluxo da amostra e o sistema analítico foram idênticos ao descrito no item 4.3.2. O tempo de concentração e elui ção da amostra foi de 1 minuto.

\subsubsection{Influência dos Ions Cloreto, Nitrato e Sulfato na Eluição de Fosfato}

Utilizando-se do mesmo sistema analítiro da Figura 2, verificou-se a influência dos íons cloreto, nitrato e sulfato na eluição do fós fato. Para isso, foram preparadas soluções deste 1 a $10^{-4} \mathrm{M}$ nestes íons. A intensidade do fluxo da amostra foi de $10 \mathrm{ml} / \mathrm{min}$, a qual apre sentava uma atividade aproximada de $6,7 \mathrm{nCi} / \mathrm{ml}$. A eluição foi feita duran te 1 minuto, com uma vazão de $1 \mathrm{ml} / \mathrm{min}$, para todas as concentrações testadas. Após a definição desses parâmetros, iniciou-se o estudo do méto'do colorimétrico para anālise de fosfato em àguas naturais. 


\subsection{Característica do Método Espectrofotomētrico}

Os métodos espectrofotométricos para a determinação de ortofosfato não são numerosos. Pequenas quantidades de fosfato são convencionalmente determinadas pelo método do azul de molibdênio, empregando-se ou não extração com solvente orgânico. 0 método do ácido molibdovanadofosfórico é recomendado para a determinação de maiores quantidades de fósforo (MARCZENKO, 1976).

0 método do azul de molibdênio tem sido citado por diversos autores (BOLTZ, 1958; KOLTHOFF e ELVING, 1961; MARCZENKO, 1976).' RUZICKA e HANSEN (1981) descrevem que a cor do composto se desenvolve segundo as se guintes reações:

$$
\begin{aligned}
& \mathrm{H}_{3} \mathrm{PO}_{4}+12 \mathrm{H}_{2} \mathrm{MoO}_{4} \rightarrow \mathrm{H}_{3} \mathrm{P}\left(\mathrm{Mo}_{12} \mathrm{O}_{40}\right)+12 \mathrm{H}_{2} \mathrm{O} \\
& \text { Mo (VI) } \stackrel{\text { redutor }}{\longrightarrow} \text { Mo (V) }
\end{aligned}
$$

0 fosfato forma com o molibdato um heteropoliácido, no qual o molibdênio, em presença de redutor, passa de um número de oxidação 6 para 5, formando uma intensa cor azul. O composto poderá ser medido espectrofotometricamente a $660 \mathrm{~nm}$, ou a $700 \mathrm{~nm}$ se o redutor utilizado for cloreto estanoso (MURPHY e RYLEY, 1962; BOLTZ, 1958). RUZICKA e HANSEN afirmam que a primeira reação é rápida e a segunda é relativamente lenta, mas como em sistemas FIA o tempo de medida do composto é constante, fica sempre assegurada a redução da mesma fração do heteropoliácido. 
4.5. Projeto do Sistema para Determinação Espectrofotométrica do Fosfato

Baseado no item 4.4, delineou-se o sistema de fluxos para a determinação colorimétrica de fosfato, mostrado na Figura 3.

Observa-se, nesta figura, que a amostra A é injetada em uma solução carregadora da Amostra $\mathrm{C}_{\mathrm{A}}$, seguindo-se as adições do reagente colorimétrico $\left(R_{1}\right)$ è em conjunto com uma solução ácida $\left(R_{2}\right)$ e do agente redutor $\left(R_{3}\right)$ nos pontos de confluência $x$ e $y$, respectivamente. A bobina $B_{R}$ foi co locada no sistema para garantir uma boa mistura dos reagentes $R_{1}, R_{2}$ e. $R_{3}$ e para permitir um tempo adequado para a formação do composto colorido, com subsequente detecção colorimétrica a $700 \mathrm{~nm}$.

Na definição do volume da amostra a ser injetada, do comprimento da bobina de reação $B_{R}$ e das intensidades dos fluxos de $C_{A}, R_{1}, R_{2}$ e $R_{3}$, foram considerados os seguintes aspectos:

a) a solução carregadora da amostra $\mathrm{C}_{\mathrm{A}}$ deveria ter a mesma composição das amostras injetadas: $\mathrm{H}_{2} \mathrm{O}$;

b) a concentração de molibdato de amônio foi fixada em $1,5 \%$ $\mathrm{m} / \mathrm{V}$, a fim de manter sempre um excesso com relação à estequiometria de reaçao;

c) a escolha do ácido e a acidez do meio foi baseada no trabalho de SHEN e DYROFF (1964), ou seja, acima de $0,7 \mathrm{~N}$ em $\mathrm{H}_{2} \mathrm{SO}_{4}$;

d) os redutores mais usados têm sido ácido ascórbico e clore to estanoso. Testes preliminares com ācido ascórbico indicaram que este redutor não oferecia ao sistema da Figura 3 boas condições de estabilidade 


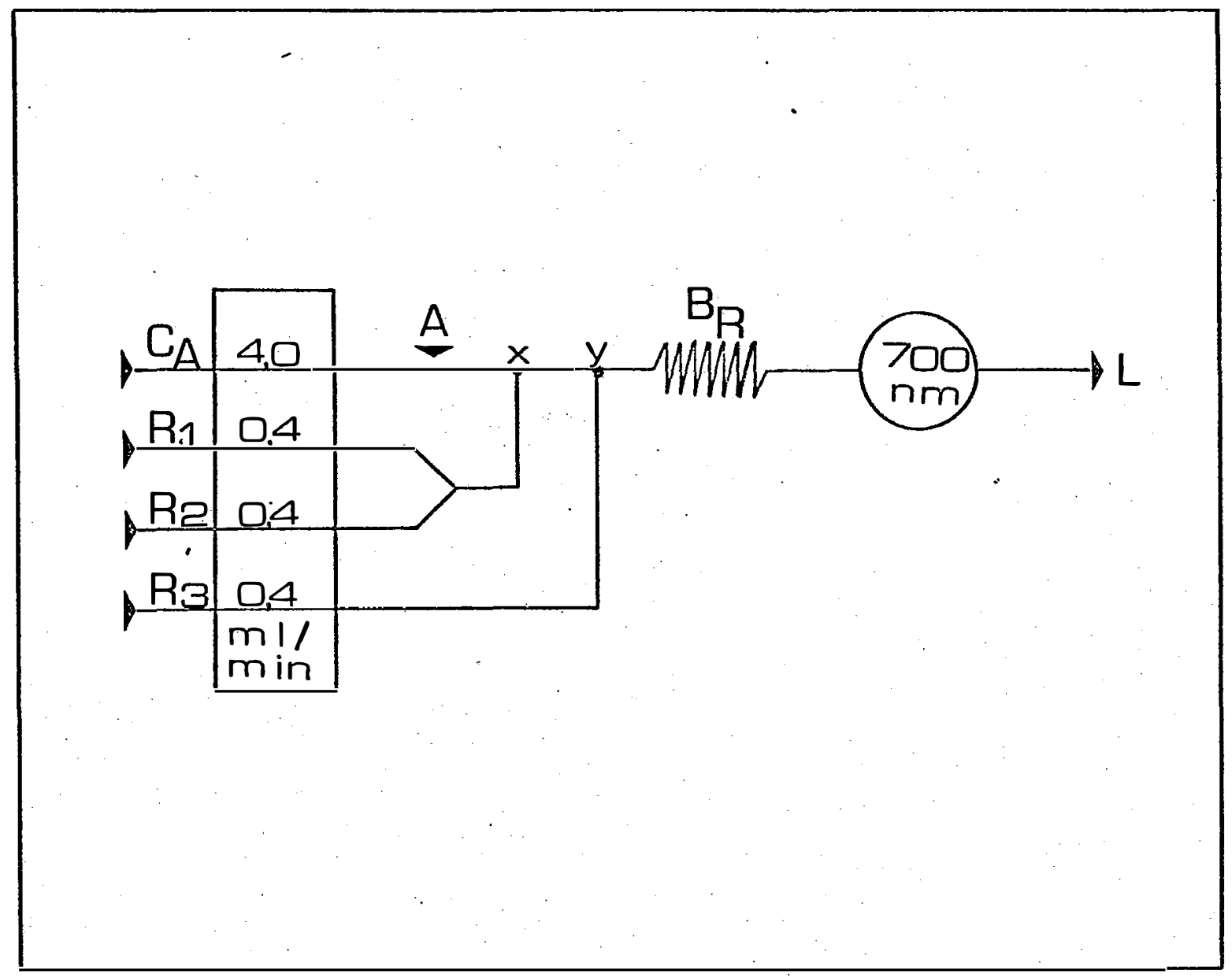

FIGURA 3 - Diagrama de fluxos utilizado para fins experimentais. $\mathrm{BP}=$ bomba peristāltica

$C_{A}=$ carregador

$\mathrm{R}_{1}=$ reagente colorimétrico

$R_{2}=$ solução ācida

$R_{3}=$ solução redutora

$A=$ amostra

$B_{R}=$ bobina de mistura e reação

$\mathbf{L}=$ descarte para o lixo 
e sensibilidade, ao contrário do cloreto estanoso. Desta forma, assumiuse o compromisso de utilizar uma solução de cloreto estanoso a $0,05 \%$. m/v nos experimentos iniciais, uma vez que esta concentração garantiria o exces so do reagente para a redução em meio ácido;

e) as intensidades dos fluxos de $C_{A}, R_{1}, R_{2}$ e $R_{3}$ deveriamser definidas de forma a permitir um método com velocidade superior a 100 deter minações por hora, bastante estável e com máxima sensibilidade possível. Assim sendo, a vazão de $C_{A}$ foi fixada em $4,0 \mathrm{ml} \cdot \mathrm{min}^{-1}$, e as intensidades dos fluxos de $R_{1}, R_{2}$ e $R_{3}$ foram estabelecidas de maneira que a zona da amostra nos pontos de confluência x e y não sofresse uma diluição acentuada, prejudicando a sensibilidade e velocidade do método;

f) o volume da amostra foi estabelecido de forma a atingirse boas condições de sensibilidade e velocidade analítica (RUZICKA e HANSEN, 1978).

Deve-se ressaltar que todos esses aspectos estão relacionados com o sistema colorimétrico anterior ao acoplamento da resina.

Após a montagem do sistema de fluxo, este foi cólocado em termos experimentais e a sensibilidade do método proposto foi o ponto principal a ser investigado. Nos ítens seguintes estão relacionados os parâme tros analíticos que foram testados durante esse estudo.

Do item 4.5.1 ao 4.5.6, estudo do sistema de fluxo sem o aco plamento da coluna de resina. Do item 4.5.7 em diante, com a coluna de re sina acoplada ao sistema analítico. 


\subsubsection{Influência da Acidez}

0 efeito da acidez na reação foi estudado através de cinco diferentes soluções de ácido sulfürico: $3 \mathrm{~N}, 4 \mathrm{~N}, 5 \mathrm{~N}, 6 \mathrm{~N}$ e $7 \mathrm{~N} . \quad 0$ volume de amostra injetado foi de $500 \mu 1$ e a bobina de reação foi fixada em 80 cm. Os padrões utilizados foram de 0,0 a 2,0 ppm de fosfato e o sistema de fluxo idêntico ao descrito em 4.5 e Figura 3.

\subsubsection{Influência da Concentração de Molibdato}

Mantendo-se a concentração da solução ácida em $4 \mathrm{~N}$, os mes mos padrões de fosfato e condições do sistema de fluxo em 4.5.1, foi anali sado o efeito da concentração de molibdato de amônio no método. As concentrações utilizadas desse reagente foram as seguintes: $0,5 \%$; $1,0 \% ; 1,5 \%$ e $2,0 \% \mathrm{~m} / \mathrm{v}$.

\subsubsection{Influência do Volume de Amostra Injetado}

0 efeito do volume de amostra injetado sobre á sensibilida de do método proposto foi verificado com a utilização do sistema de fluxo da Figura 3 e mantendo-se constante os demais parâmetros do experimento an teriormente descrito. Os volumes de amostra testados variaram de 100 a $1000 \mu 1$. A concentração da solução de molibdato de amônio utilizada foi de $1,5 \% \mathrm{~m} / \mathrm{v}$.

4.5.4. Influência do Comprimento de Onda na Absorção do Composto

0 espectro de absorção do composto colorido foi obtido utilizando-se de um padrão de 2,0 ppm de fosfato $(500 \mu 1)$, onde este padrão 
foi injetado em triplicata para cada comprimento de onda testado. A varre dura foi feita de 500 a $800 \mathrm{~nm}$, em intervalos de 25 e $50 \mathrm{~nm}$. 0 sistema de fluxo e demais reagentes foram idênticos ao descrito em 4.5.3.

4.5.5. Influência do Cloreto Estanoso e Definição da Bobina de Reação

O efeito da concentração de cloreto estanoso no método em es tudo foi observado mantendo-se as mesmas condições analíticas descritas no item 4.5.3, sem o emprego da amostra. Este estudo foi efetivado com o objetivo de se observar as alterações provocadas na estabilidade da linha de base do sistema analítico. Utilizaram-se as concentrações desse reagente, variando de 0,0 a $1,0 \% \mathrm{~m} / \mathrm{v}$.

Neste mesmo sistema, procurou-se definir o comprimento da bo bina de reação, substituindo-se o carregador $\mathrm{C}_{\mathrm{A}}$ da amostra por um padrão de 2,0 ppm de fosfato. Desta forma, este padrão foi introduzido no sistema continuamente, evitando assim uma possível dispersão da zona da amostra, que ocorre quando esta é injetada (MEDEIROS, 1979). A concentração de cloreto estanoso foi de $0,05 \% \mathrm{~m} / \mathrm{v}$.

\subsubsection{Influência do Eluente na Reação Colorimētrica de Fosfato}

Mantendo-se as mesmas condições analíticas do item 4.5.3, e injetando-se um volume de amostra de $500 \mu 1$, verificou-se o efeito do eluente na reação colorimétrica do fosfato. Foram preparadas soluções de clore to de sódio, nitrato de sódio e nitrato de amônio $0,25 \mathrm{M}$, as quais substituí. ram o carregador $\mathrm{C}_{\mathrm{A}}$ da amostra (água). Os padrões utilizados, variando de 
0,0 a 2,0 ppm de fosfato, foram preparados na mesma matriz e concentração dos carregadores.

\subsubsection{Influência de Alguns İons na Retenção de Fosfato na Coluna de Resina}

Para verificar o efeito de alguns ânions na retenção de fos fato na coluna de resina, fixou-se a solução de nitrato de amônio 0,25M co mo carregador $\mathrm{C}_{\mathrm{A}}$ da amostra e substituiu-se o "1oop" da amostra por uma co luna de resina de $3,5 \mathrm{~cm}$ construída conforme o item 3.4 . Inicialmente, con centraram-se na coluna padrões contenḋo desde 0,0 a 0,1 ppm de fosfato, com um fluxo de $10 \mathrm{ml} / \mathrm{min}$ durante 1 minuto. A seguir, foram preparados pa drões de fosfato (de 0,0 a 0,1 ppm) em soluções contendo 100 ppm de sulfato, 300, 100 e 50 ppm de cloreto e 100 ppm de nitrato. Estas concentrações basearam-se nas quantidades em que os referidos íons ocorrem normalmente em águas naturais. Segundo OLTMAN (1967), APHA/AWWA/WPCF (1975) e KLEIN (1959), de um modo geral, a concentração máxima de nitrato encontrada em águas naturais está em torno de 50 ppm. Com relação ao ânion sulfato, de acordo com ROBBINS et alii (1973), ADAMSKI et alii (1975)e KRUG et alii (1977), na referida matriz as concentrações mais elevadas do referido ânion estão em torno de 60 a 70 ppm, raramente excedendo a 100 ppm. Para o cloreto, nos trabalhos de KLEIN (1959), APHA/AWWA/WPCF (1975) e MASON (1971) não foram encontradas em águas naturais concentrações superio res a $250 \mathrm{ppm}$.

0 mesmo procedimento foi efetuado para colunas de 4,5, 5,5

e $6,5 \mathrm{~cm}$. 
A concentraçao de ācido sulfúrico foi $4 \mathrm{~N}$, molibdato de amô nio $1,5 \% \mathrm{~m} / \mathrm{v}$ e cloreto estanoso $0,05 \% \mathrm{~m} / \mathrm{v}$. A Figura 4 mostra o sistema $\mathrm{u}-$ tilizado.

4.5.8. Efeito do Tempo de Prē-Concentração da Amostra

Empregando-se a coluna de resina de $3,5 \mathrm{~cm}$, e utilizando-se o mesmo sistema analítico e demais condições como descrito em 4.5.7, variou se o tempo de concentração da amostra de 30 a 120 segundos (correspondente a volumes de 5 a $20 \mathrm{ml}$ ), para verificar seu efeito na sensibilidade ao méto do. Os padrões utilizados foram de 0,010, 0,025, 0,050 e 0,100 ppm de fosfato.

\subsubsection{Efeito do $\mathrm{pH}$ ou das Formas de Fosfato}

Com a utilização do diagrama de fluxos da Figura 4, verificou-se experimentalmente a influência do $\mathrm{pH}$ das soluções de fosfato, princi palmente no processo de retenção e eluição da resina. Preparou-se uma série de padrões, contendo desde 0,000 a 0,100 ppm de fosfato, a qual apresentou pH em torno de 5,5. Em seguida, prepararam-se outras duas séries dos mes mos padrões, uma em $\mathrm{pH}$ 4,0 e outra em $\mathrm{pH}$ 9,0, ajustado com ácido nítrico di luído e hidróxido de amônio destilado, respectivamente.

As condições analíticas foram idênticas às descritas no item $4 \cdot 5 \cdot 7$. 


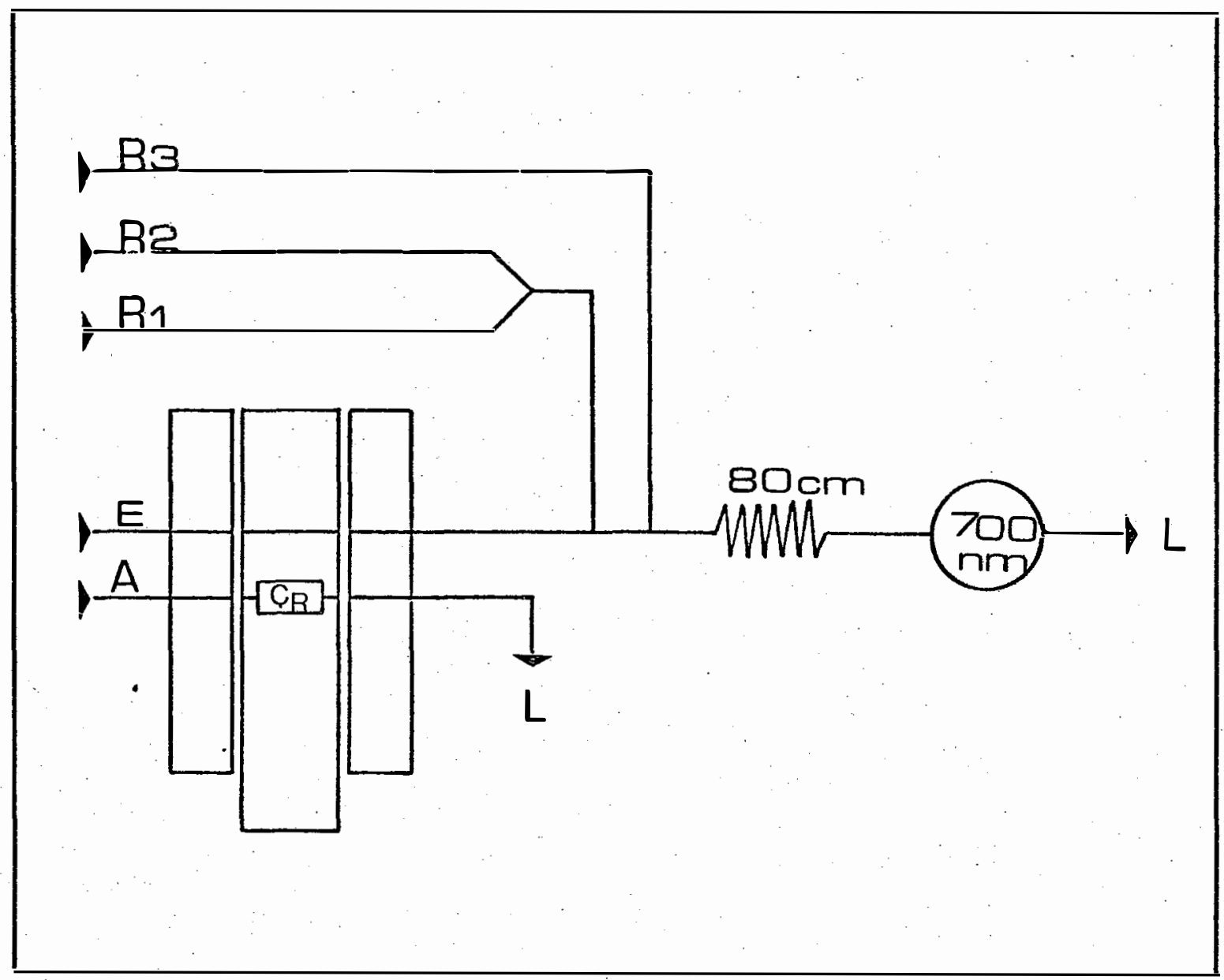

FIGURA 4 - Diagrama de fluxos utilizado para a determinação de fosfato em àguas naturais.

$\mathrm{R}_{3}=$ cloreto estanoso $0,05 \% \mathrm{~m} / \mathrm{V} ; \mathrm{fluxo} 0,4 \mathrm{ml} / \mathrm{min}$

$\mathrm{R}_{2}=$ ácido sulfúrico $4 \mathrm{~N}$; fluxo $0,4 \mathrm{ml} / \mathrm{min}$

$\mathrm{R}_{1}=$ molibdato de amônio $1,5 \% \mathrm{~m} / \mathrm{V}$; fluxo $0,4 \mathrm{ml} / \mathrm{min}$

- $\quad E=$ nitrato de amônio $0,25 \mathrm{~N}$; fluxo $4 \mathrm{ml} / \mathrm{min}$

$\mathrm{C}_{\mathrm{R}}=$ coluna de resina

$\mathrm{L}$ = saída para o descarte

$A=$ amostra 


\subsubsection{Caracterīsticas Analíticas}

\subsubsection{Exatidão}

0 teste de exatidão foi realizado de acordo com o procedimen to recomendado por FRITZ e SCHENK (1976), ou seja, através da utilização da técnica da adição padrão.

Este teste foi realizado adicionando-se diferentes quantidades de fosfato a amostras je água natural. As amostras foram injetadas em triplicata no sistema, cujos parâmetros foram os mesmos do experimento descrito no item 4.5.7.

\subsubsection{Precisão}

Duas amostras de águas naturais com diferentes concentrações de fosfato, foram analisadas com a utilização do diagrama de fluxos da Figu ra 4, através de 10 injeções consecutivas de cada uma delas. Os demais pa râmetros seguem o item 4.5.7. A precisão foi avaliada em termos do desvio padrão porcentual das medidas obtidas. 


\section{RESULTADOS E DISCUSSĀO}

\subsection{Influência da Intensidade do Fluxo da Amostra}

De acordo com o procedimento descrito em 4.3.1, a influência da intensidade de fluxo na retenção (R) de fosfato na coluna de resina pode ser observado pelo exame da curva da Figura 5. Considerou-se o núme ro de contagens obtidas com a vazão (V) de $1 \mathrm{ml} / \mathrm{min}$ como $100 \%$ e para as demais vazões (2, 5 e $10 \mathrm{ml} / \mathrm{min}$ ) uma porcentagem relativa a este. Nota-se por esta figura que à medida que foi aumentada a intensidade de fluxo, ocorreu uma menor retenção de fosfato na coluna de resina. Este fato pode rā ser compreendido baseado nas considerações feitas por SAMUELSON (1963). Segundo este autor, a retenção dos íons na resina é dependente do processo de cinética de troca iônica. Ou seja, o equilíbrio entre os íons sera tão mais favorecido na zona de troca quanto mais baixa a vazão do carregador da amostra. A vazão de $10 \mathrm{ml} / \mathrm{min}$ foi a escolhida pois, mesmo com uma perda de aproximadamente $32 \%$ no número de contagens, conseguiu-se uma velo cidade analítica dez vezes superior. 


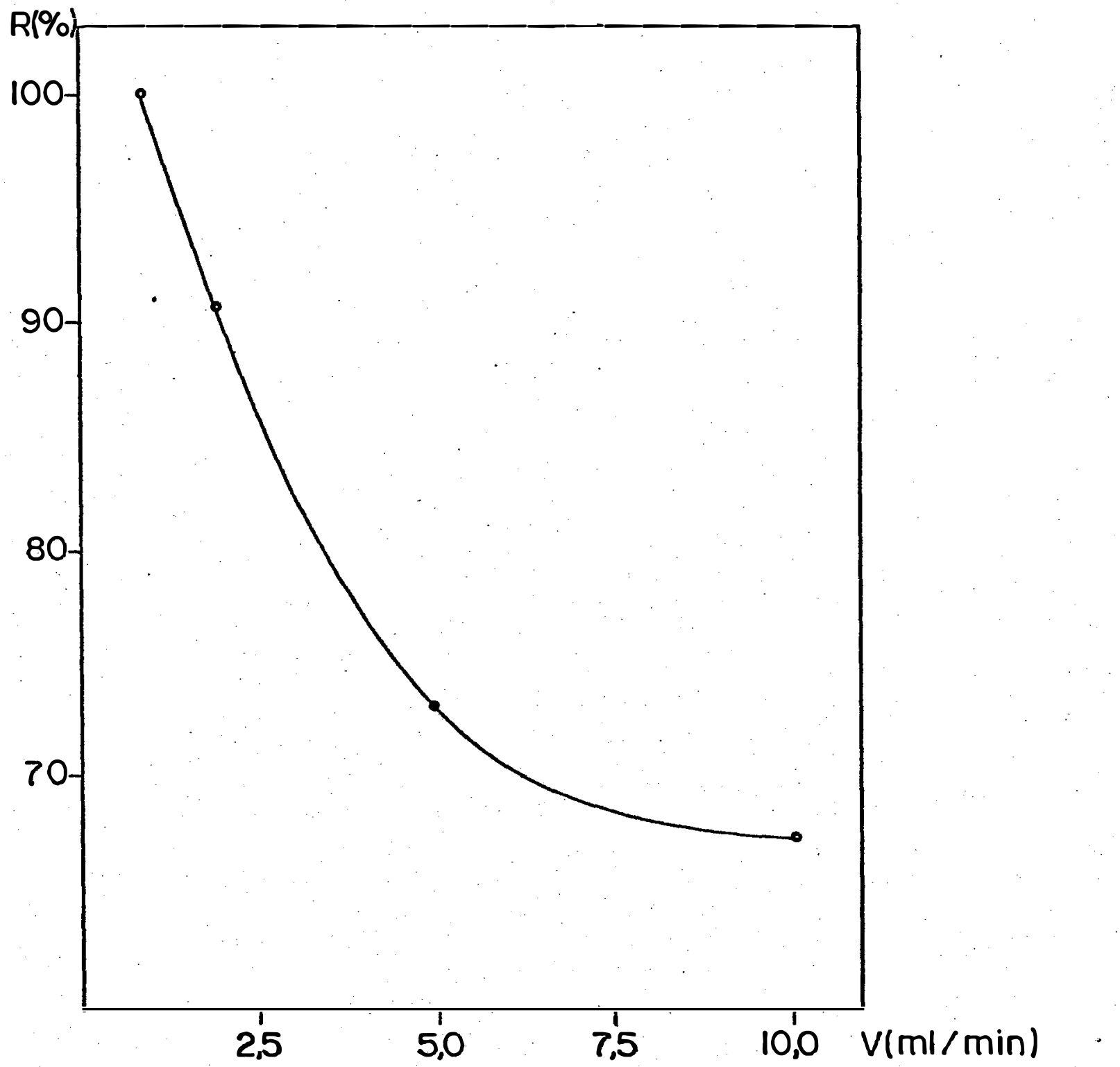

FIGURA 5 - Influência da intensidade de fluxo da amostra na pré-concentração de fosfato na coluna de resina. R é a retenção de fosfato e $V$ a vazão utilizada na prē-concentração. 


\subsection{Influência da Intensidade de Fluxo e do Tempo de Eluição Necessārio}

Segundo o procedimento descrito no item 4.3.2, observou-se a influência da intensidade de fluxo e o tempo necessário de eluição. Pelo exame das curvas da Figura 6, nota-se que, com exceção da vazão de $1 \mathrm{ml} /$ min, para todas as demais estudadas o tempo de 30 segundos foi suficiente pa ra eluir praticamente todo o fosfato radioativo retido na coluna. Uma quantidade inferior a $1,0 \%$ ficou retida. Ressalta-se que as demais curvas para os outros tempos de eluição não foram apresentadas, visto que elas eram praticamente idênticas à curva $B$, com exceção ao fluxo de $1 \mathrm{ml} / \mathrm{min}$.

Assim sendo, na definição do método colorimétrico, poder-seia optar pelas vazões de $2,4,6,8$ ou $10 \mathrm{ml} / \mathrm{min}$, uma vez que todas apresen taram praticamente a mesma eficiência de eiuição para o tempo de 30 segun dos. Como neste sistema estas vazões seriam a do carregador $\mathrm{C}_{\mathrm{A}}$ da $\operatorname{amos}-$ tra, seria necessārio levar em consideração a velocidade analítica e a ciné tica da reação. Como a vazão de $2 \mathrm{ml} / \mathrm{min}$ não oferecia boas condições de velocidade, inicialmente assumiu-se o compromisso de utilizar $4 \mathrm{ml} / \mathrm{min}$, uma vez que a mesma permitiria uma boa velocidade de análise e condições para o desenvolvimento da reação colorimétrica. 


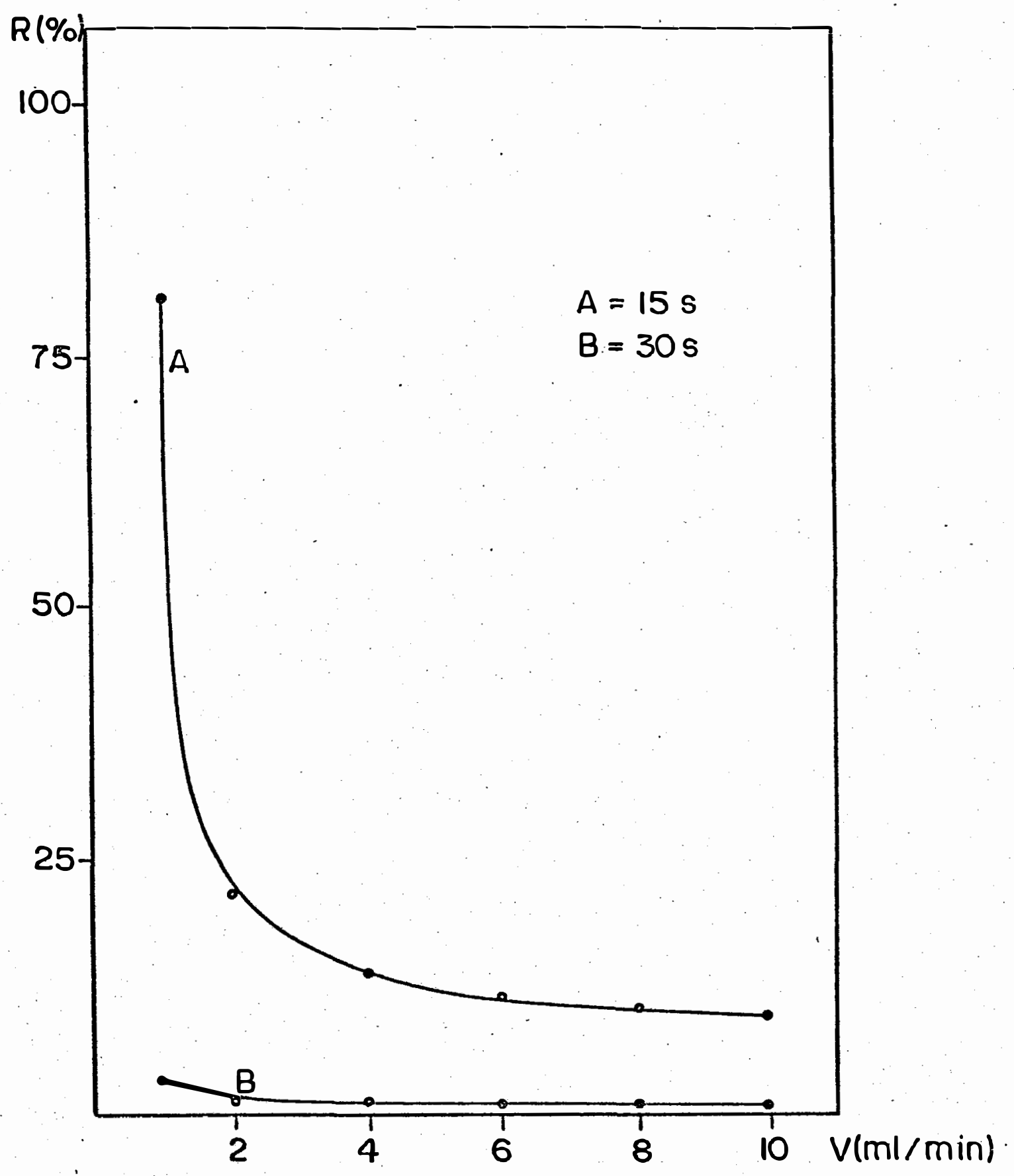

FIGURA 6 - Influência da intensidade do fluxo e tempo de eluiçãona retenção de fosfato utilizando NaCl-iN a pH 5,00 como eluente. 
5.3. Relação Entre a Intensidade de Fluxo de Eluição e as Concentrações do Eluente

Com base no procedimento descrito no item 4.3.3, foi obtido o gráfico da Figura 7.

Nota-se, por esta figura, que mantendo constante a quantidade de cloreto de sódio na unidade de tempo, o efeito de eluição foi praticamente o mesmo em todas as situações, ou seja, a eficiência de eluição se mantém constante quando na unidade de tempo a quantidade do eluente que pas sa pela coluna for equivalente.

Esta consideração pode ser feita visto que nessa ocasião a taxa de contagens da radiação de fundo foi de $32 \mathrm{cpm}$ e para qualquer um dos quatro tratamentos, as contagens obtidas no final da eluição se aproximaram bastante deste valor.

Em vista desse resultado, na definição do carregador de amostra do método colorimétrico com resina poderiam ser utilizados quaisquer intensidades de fluxo, desde que se mantivesse a mesma relação. 


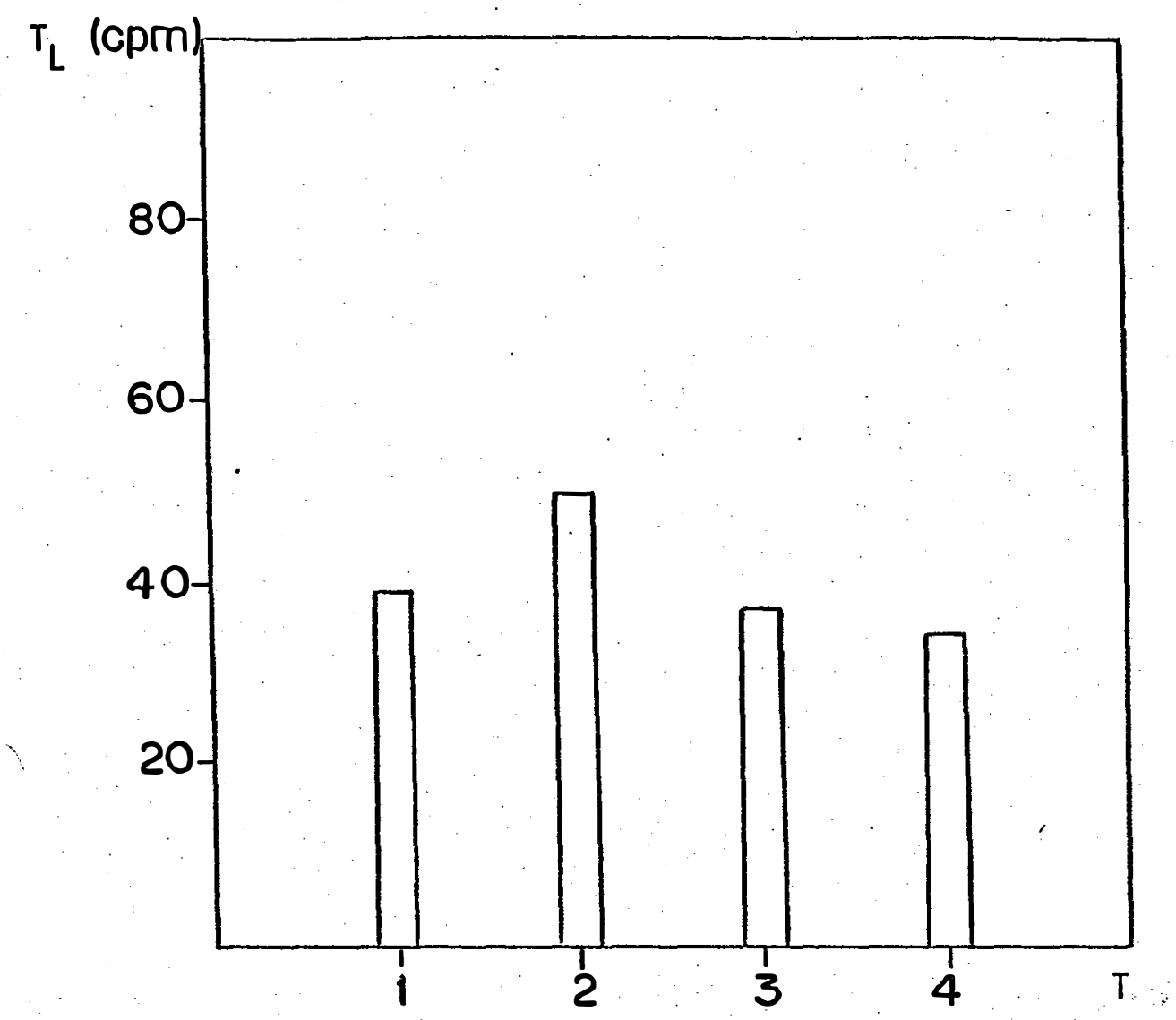

FIGURA 7 - Relação entre as intensidades de fluxo de eluição e as concentrações do eluente. $T_{L} \bar{e}$ a taxa líquida de contagem :e $T$ os tratamentos.

$$
\begin{array}{ll}
1-1 \mathrm{ml} / \mathrm{min}-\mathrm{NaCl}-1 \mathrm{~N} & \text { eq } \mathrm{mg} \mathrm{NaCl} / \mathrm{min} \\
2-2 \mathrm{ml} / \mathrm{min}-\mathrm{NaCl}-0,5 \mathrm{~N} & 1,0 \\
3-5 \mathrm{ml} / \mathrm{min}-\mathrm{NaCl}-0,2 \mathrm{~N} & 1,0 \\
4-10 \mathrm{ml} / \mathrm{min}-\mathrm{NaCl}-0,1 \mathrm{~N} & 1,0
\end{array}
$$


5.4. Influência dos Ions Cloreto, Nitrato e Sulfato na Eluição de Fosfato

Foi verificado, segundo procedimento descrito no item 4.3.4, o efeito de várias concentrações dos íons cloreto, nitrato e sulfato quando empregados como eluentes.

Os resultados encontram-se na Tabela 2 , onde observa-se que todos esses ions exerceram uma grande influência na retenção de fosfato, quando concentrações superiores a $10^{-2} \mathrm{M}$ foram utilizadas.

Nota-se que todo o fosfato concentrado na coluna continuou retido quando utilizaram-se soluções contendo $10^{-4}$ e $10^{-3} \mathrm{M}$ em cloreto. Pa ra nitrato e sulfato nas mesmas concentrações, observa-se que uma quantidade inferior a $4 \%$ foi eluída. Somente a partir das soluções $10^{-2} \mathrm{M}$ é que o efeito foi bastante pronunciado. Para as concentrações $10^{-1} \mathrm{M}$ e $1 \mathrm{M}$ a porcentagem de fosfato retido foi praticamente a mesma. Em todas as situações ficou evidente que para uma solução $1 M$ destes ỉons, com uma vazão de $1 \mathrm{ml} / \mathrm{min}$ durante 1 minuto, a eluição do fosfato foi praticamente total.

De uma forma geral, poder-se-ia utilizar solução de cloreto, nitrato e sulfato na concentração e vazão já descritas (ou similares, segun do item 5.3) para eluir o fosfato retido na resina. 
Tabela 2 - Influēncia dos Tons $\mathrm{Cl}^{-}, \mathrm{SO}_{4}^{2-}$ e $\mathrm{NO}_{3}^{-}$na retenção de fosfato na coluna de resina.

\begin{tabular}{|c|c|c|c|}
\hline \multirow{2}{*}{$\begin{array}{c}\text { Concentração } \\
\therefore(\text { inolar }):\end{array}$} & \multicolumn{3}{|c|}{$\%$ de Fosfato Retido na Coluna } \\
\hline & $\mathrm{Cl}^{-}$ & $\mathrm{SO}_{4}^{2-}$ & $\mathrm{NO}_{3}^{-}$ \\
\hline $10^{-4}$ & 100,00 & 98,31 & 98,82 \\
\hline $10^{-3}$ & 100,00 & 96,47 & 96,17 \\
\hline $10^{-2}$ & 83,20 & 3,76 & 17,92 \\
\hline $10^{-1}$ & 1,92 & 1,66 & 1,54 \\
\hline $10^{\circ}$ & 0,94 & 0,92 & 0,74 \\
\hline
\end{tabular}




\subsection{Influência da Acidez (Método Espectrofotométrico)}

De acordo com o procedimento descrito no item 4.5.1, verificou-se o efeito da acidez no método proposto. Observa-se, pelo exame da Figura 8, um aumento significativo na absorbância do composto quando se dimi nuiu a concentração da solução ácida. Dessa forma, poder-se-ia optar pe1a concentração $3 \mathrm{~N}$ em ácido sulfúrico. Ocorre que, com esta acidez, notava-se a interferência de silício (100 ppm) e uma intensa coloração azul era formada ao longo do sistema analítico, provocando a subida e instabilidade da linha de base. Dessa forma, escolheu-se a concentração $4 \mathrm{~N}$ em ácido sul fúrico, onde estes inconvenientes não eram notados. Ressalte-se que a con centração ācida na bobina de reação para a solução $4 \mathrm{~N}$ em ácido sulfúrico era aproximadamente $0,4 \mathrm{~N}$ e que este valor entrava em discordância com o apre sentado por SHEN e DYROFF (1964). Segundo os autores, para evitar-se a in terferência de silício (100 ppm), a concentração ácida final da reação deve ria ser igual ou superior a $0,7 \mathrm{~N}$ em ácido sulfúrico. Uma vez que nesta re ação o silício é um interferente, e que a cinética de reação é importante, tem-se que considerar a seguinte situação: os autores fizeram a determinação colorimétrica manualmente, onde as leituras dos padrões e amostras eram feitas num intervalo de 5 a 100 min após a adição do agente redutor, ao passo que no sistema de fluxo contínuo, essa reação se processa em torno de 15 segundos após a adição do agente redutor. Possivelmente, nestas condições, a cinética de reação do silício foi menos favorecida que a do fosfato. 


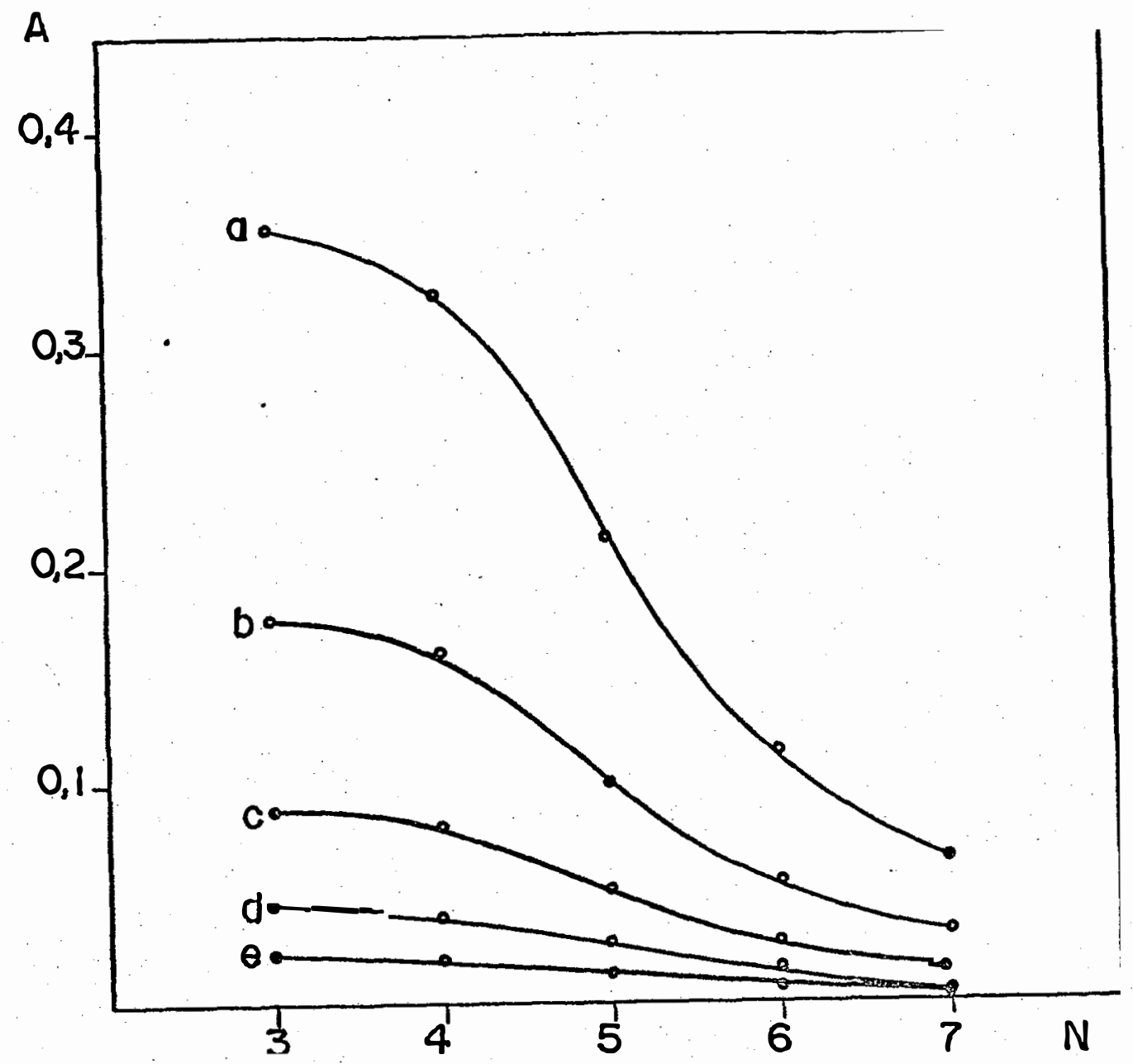

FIGURA 8 - Influência da acidez na absorbância do composto. A - valores de absorbância dos padrões $\mathrm{N}$ - normalidade das soluções de ácido sulfúrico

a - 2,0 ppm fosfato

b - 1,0 ppm fosfato

c $-0,5 \mathrm{ppm}$ fosfato

d $-0,2 \mathrm{ppm}$ fosfato

e $=0,1 \mathrm{ppm}$ fosfato 


\title{
5.6. Influência da Concentração de Molibdato
}

\begin{abstract}
Conforme o procedimento descrito no item 4.5.2, foram obtidas as curvas relacionando as concentrações de molibdato estudadas e diferentes quantidades de fosfato.
\end{abstract}

Pode ser observado na Figura 9 que, para as condições do sis tema proposto, o aumento da concentração de molibdato promove um aumento na absorção do composto. Entretanto, para a concentração a $2 \%$ de molibdato, notou-se a formação de uma intensa coloração azul ao longo do percurso analítico, provocando uma instabilidade e subida da linha de base do sistema. Sendo assim, a concentração a $1,5 \% \mathrm{~m} / \mathrm{v}$ foi escolhida, visto que, nestas con dições, a linha de base era estável.

\subsection{Influência do Volume de Amostra Injetado}

Conforme procedimento descrito no item 4.5.3, verificou-se o efeito do volume de amostra injetado.

Observa-se pelo exame das curvas da Figura 10, ó significati vo aumento na absorbância do composto colorido com o aumento do volume in jetado no sistema (Va). Esse volume foi definido em função da sensibilida de e velocidade analíticas desejadas. A relação entre sensibilidade e velocidade analítica é bastante conhecida e estudada. 0 intervalo de tempo correspondente entre o sinal registrado e o retorno à linha de base (tempo de limpeza), varia com o volume injetado; quanto maior esse volume, maior a sensibilidade (maior o sinal) e maior será o tempo de limpeza, o que comprometerā sobremaneira a velocidade analítica (RUZICKA e HANSEN, 1978; KRUG 


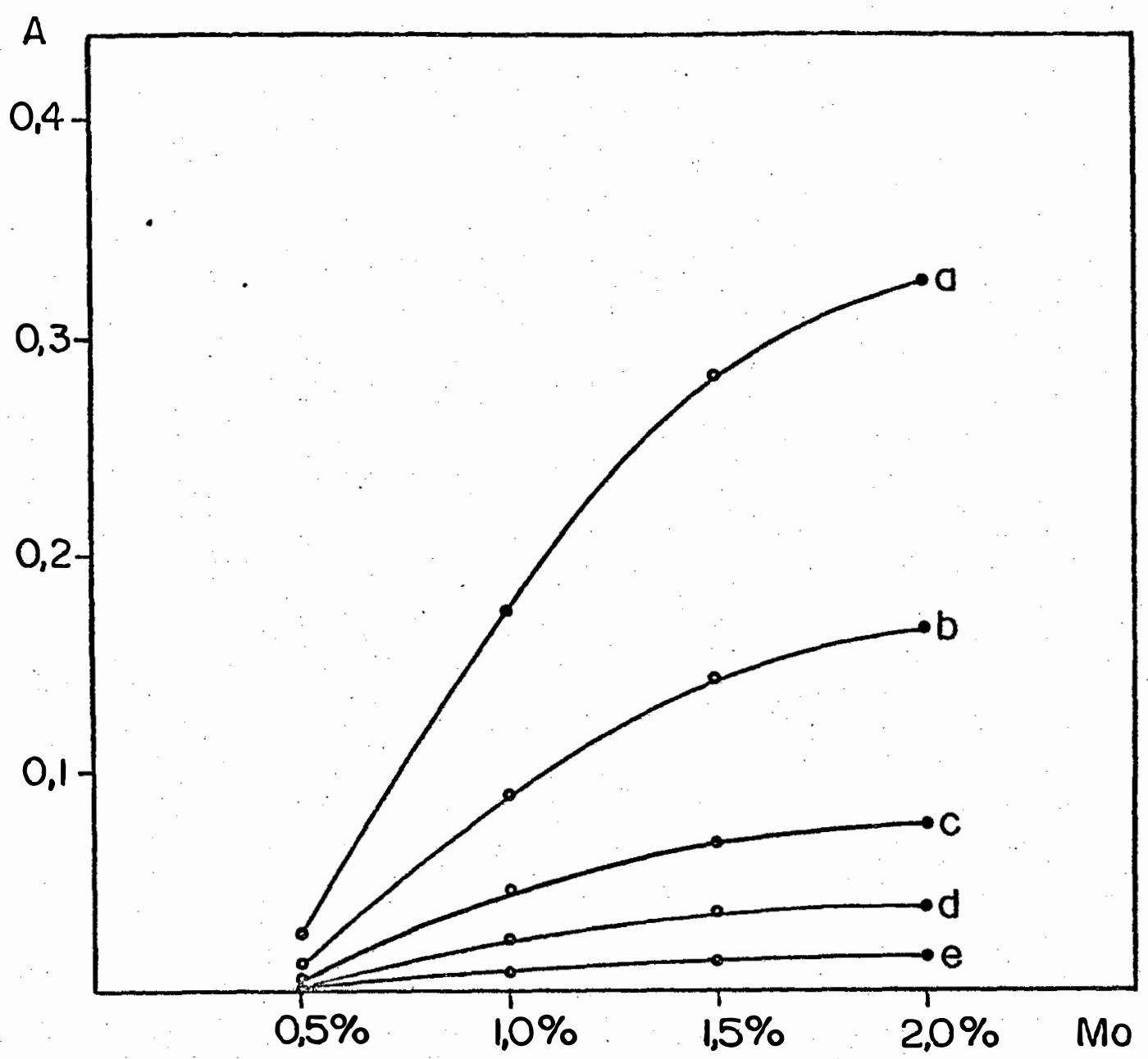

FIGURA 9 - Influência da concentração de molibdato. Mo é a concentração de molibdato de amônio em $\%(\mathrm{~m} / \mathrm{V})$ e $\mathrm{A}$ a absorbância.
a - 2,0 ppm fosfato
b - 1,0 ppm fosfato
c $-0,5$ ppm fosfato
d - 0,2 ppm fosfato
e $-0,1 \mathrm{ppm}$ fosfato 


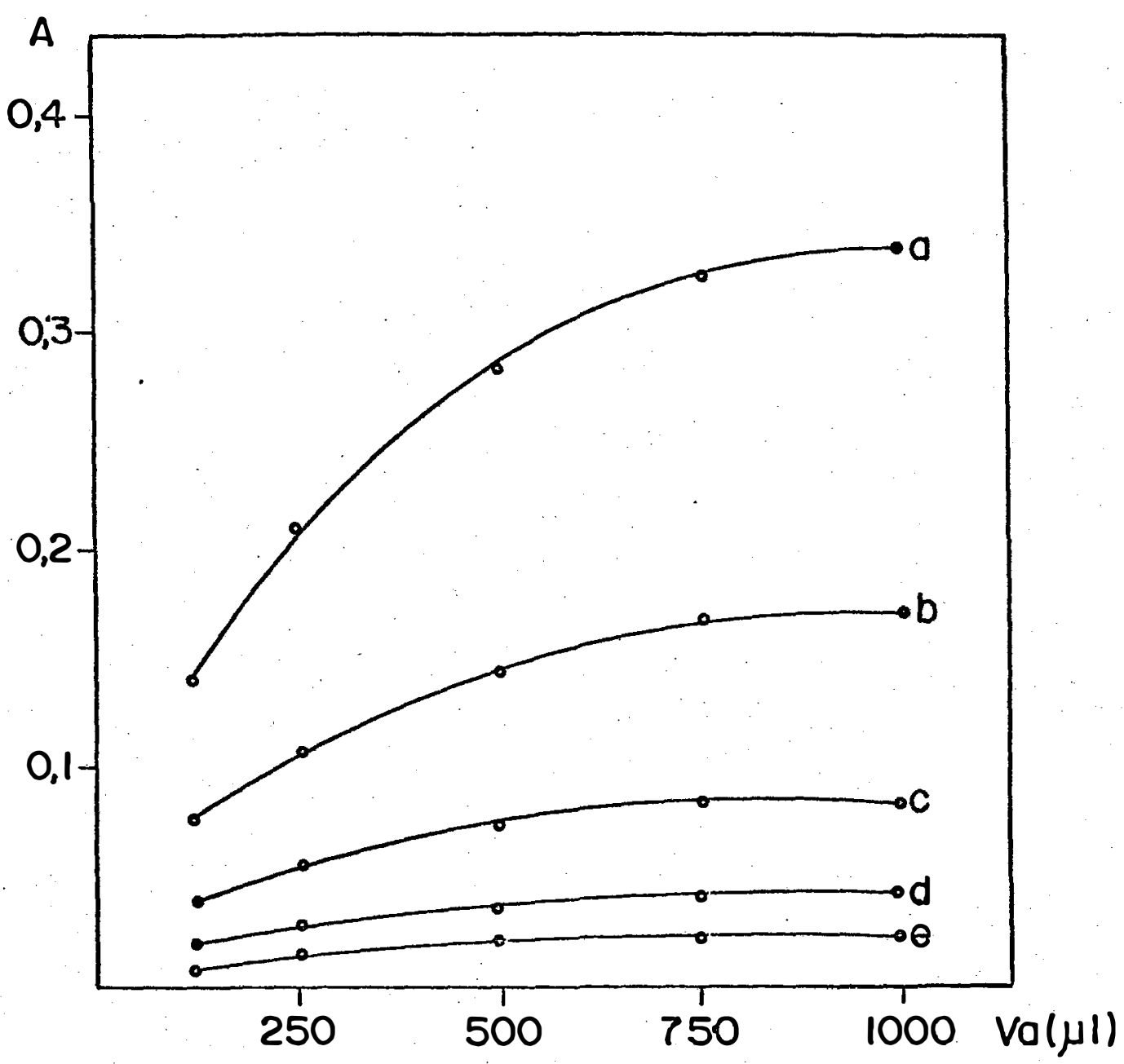

FIGURA 10 - Influência do volume de amostra injetado. Va são os volumes em microlitros e A a absorbância.
a - 2,0 ppm fosfato
b - 1,0 ppm fosfato
c - 0,5 ppm fosfato
d - 0,2 ppm fosfato
e $-0,1 \mathrm{ppm}$ fosfato 
et alii, 1981). Dessa forma, a escolha do volume de amostra de $500 \mu 1$ cer tamente não viria comprometer a velocidade analítica, embora, nestas condições, a sensibilidade possa ser ligeiramente afetada.

\subsection{Espectro de Absorção do Compos to.}

Conforme procedimento descrito no item 4.5.4, verificou-se a influência do comprimento de onda na absorção do composto. De acordo com MARCZENKo (1976), a absorbância do azul de molibdênio é muito dependente do meio (aquoso ou orgânico), do redutor e da acidez da fase aquosa. Desta forma, utilizando-se de um meio aquoso onde a acidez foi de aproximadamente 0,4N em ácido sulfúrico, e tendo como agente redutor o cloreto estanoso, ob̆teve-se o máximo de absorção do composto a $700 \mathrm{~nm}$ (Figura 11). Este resultado está em concordância com o encontrado por MURPHY e RILEY (1962) e BOLTZ (1958). Estes autores citam que quando se utiliza cloreto estanoso como redutor, o máximo de absorção do composto se encontra a $700 \mathrm{~nm}$. 


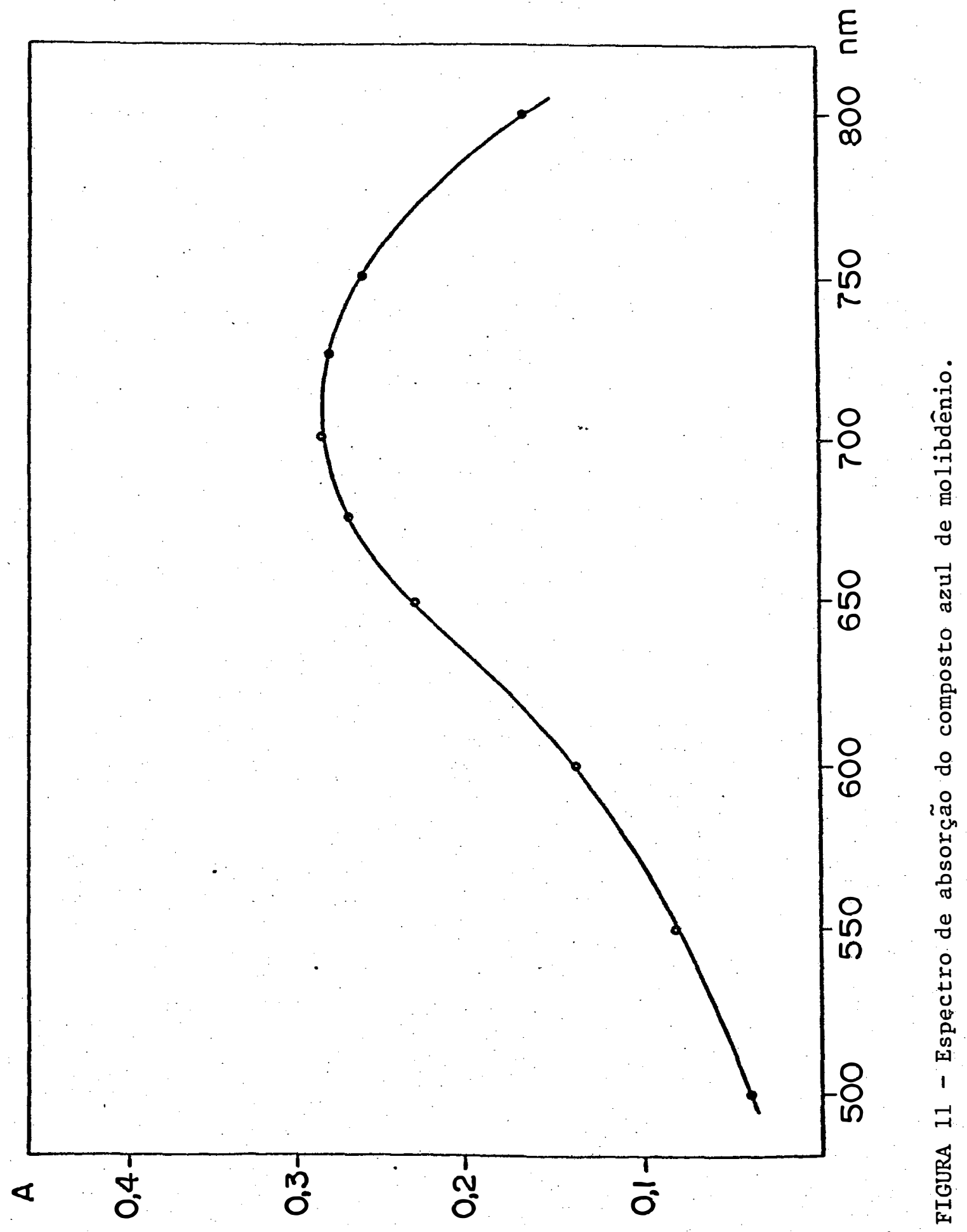


5.9. Influência do Cloreto Estanoso e Definição da Bobina de Reação

Em função dos dados obtidos segundo procedimento descrito no item 4.5.5, representados na Figura 12, observa-se a influência da concentração de cloreto estanoso no método em estudo.

Nota-se que, aumentando a concentração de cloreto estanoso, ocorre um deslocamento positivo da linha de base, decorrente do desenvolvi mento de uma coloração, provavelmente devida à redução do ācido molíbdico.

Esta redução foi mais intensa quanto maior a concentração do redutor. Dessa forma, assumindo um compromisso com a sensibilidade e estabilidade do sistema, optou-se pela concentração de $0,05 \% \mathrm{~m} / \mathrm{v}$ de cloreto estanoso.

Outro aspecto seria quanto à estabilidade do composto forma do. Este efeito pode ser notado na Figura 13 através da injeção de um padrão de 2,0 ppm de fosfato, em configuração de volume infinito. Observase claramente que, com aproximadamente 2,5 minutos de reação após a parada do fluxo, o produto formado tende a decrescer em intensidade de cor. No sistema de injeção em fluxo em questão, este problema deixa de existir, uma vez que a reação se processa de forma constante, para ca amostra injetada, em aproximadamente 10 segundos, evitando, desta maneira, inconvenien tes relacionados com a estabilidade do composto. 


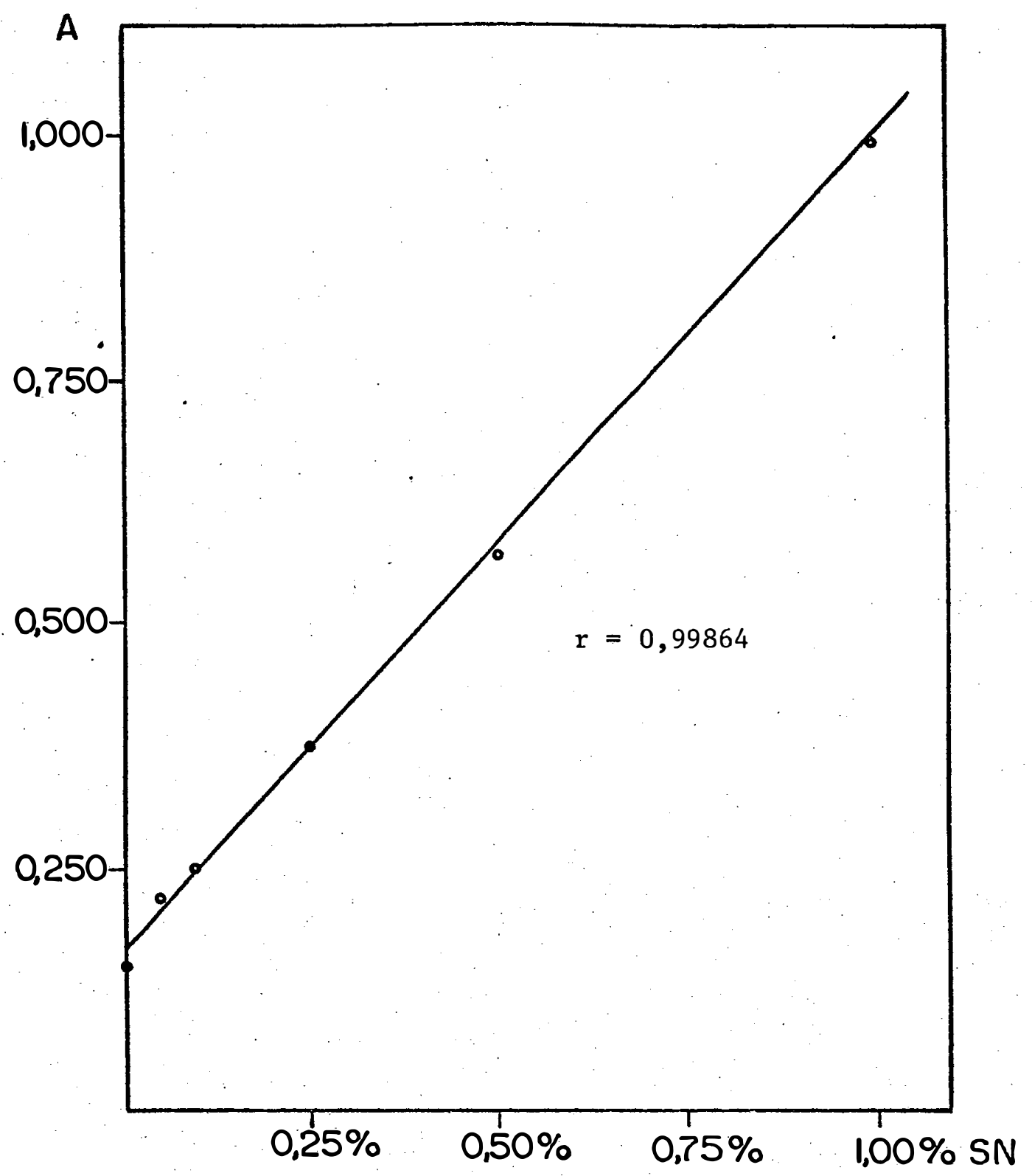

FIGURA 12 - Efeito da concentração de cloreto estanoso no sistema analítico.SN é a concentração de cloreto estanoso em \% (m/v). 
Na mesma Figura 13, pode-se definir o comprimento da bobina de reação, onde nota-se a formação de dois patamares. 0 menor foi obtido através da injeção da amostra em configuração de volume infinito, fixando a bobina de reação em $80 \mathrm{~cm}$. Com a parada dos fluxos (stop-flow), observouse que com aproximadamente mais 1 minuto a reação se desenvolveu quase que totalmente. Para estas condições, uma bobina de reação de mais de $500 \mathrm{~cm}$ deveria ser utilizada, o que não seria conveniente, pois, a velocidade analítica ficaria sobremaneira comprometida, além de uma acentuada dispersão da amostra injetada. Desta forma, a bobina de reação de $80 \mathrm{~cm}$ foi mantida.

Em experimentos preliminares, utilizando-se o ācido ascōrbico como redutor, e idêntico sistema analítico, observou-se que para se conseguir resultado semelhante, foi necessārio utilizar solução a $10 \% \mathrm{~m} / \mathrm{v}$ do citado redutor e de molibdato de amônio. Respectivamente, estas soluções apresentavam concentração 200 e 6 vezes superiores ao definido neste traba1ho, além da necessidade de uma solução de bismuto como catalisador da reação. Foi observado também que, nestas condições, a reação não conferiu ao sistema de fluxo a mesma estabilidade. 


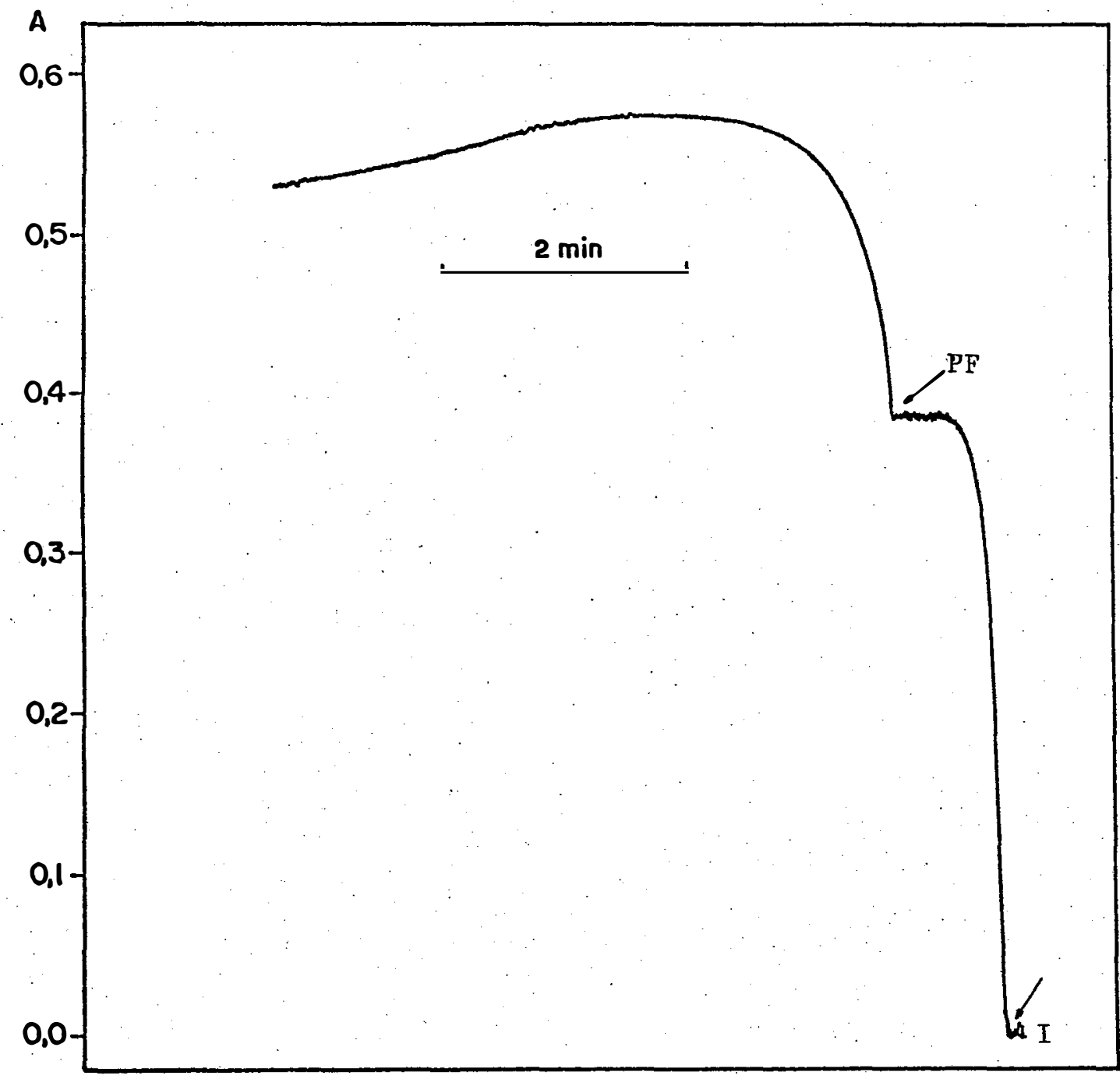

FIGURA 13 - Cinética do desenvolvimento de cor do azul de molibdênio. PF - parada dos fluxos

I - injeção da amostra 


\subsection{Influência do Eluente na Reação Colorimétrica de Fosfato}

Segundo procedimento descrito no item 4.5.6, verificou-se o efeito do eluente na reação colorimétrica do fosfato. A solução $1,00 \mathrm{~N}$ em cloreto de sódio, anteriormente utilizada como eluente, apresentou alguns inconvenientes quando testada no sistema colorimétrico, tais co mo: grande instabilidade da linha de base do sistema analítico e leitura significativa do padrão 0,0 ppm de fosfato (branco), devido a problemas de refração. 0 mesmo sucedeu com relação a 0,50N. Desta forma, a concen tração a $0,25 \mathrm{~N}$ foi escolhida, uma vez que, nestas condições, estes inconvenientes eram sobremaneira minimizados. Ressalte-se também que, segundo resultado apresentado no item 5.4 deste capítulo (Tabela 2), quando uma so lução $10^{-1} \mathrm{M}$ em cloreto de sódio foi empregada, apenas $2,0 \%$ do fosfato continuou retido na coluna. Nesta linha de raciocínio, era de se esperar que a solução $0,25 \mathrm{~N}$ garantisse uma eluição do fosfato superior a $98 \%$. Com base na referida tabela, as mesmas considerações poderiam ser feitas ao íon nitrato na mesma concentração, visto que, para as concentrações 0,5 e $1,0 \mathrm{~N}$, surgiram os mesmos inconvenientes no sistema colorimétrico. Com relação ao sulfato, foi descartada a possibilidade de sua utilização como eluente, pois, mesmo as soluções de concentração inferior a $10^{-1} \mathrm{M}$ provocavam grande instabilidade no sistema colorimétrico.

Outro aspecto considerado foi o relativo à vazão de eluição utilizada. Tendo sido definido uma vazão de $4 \mathrm{ml} / \mathrm{min}$ e concentração do e luente a $0,25 \mathrm{~N}$, foi possível associar esta condição àquela na qual se empregou $1 \mathrm{ml} / \mathrm{min}$ do eluente na concentração $1 \mathrm{~N}$ (esta associação pôde ser feita em função dos resultados obtidos no item 5.3 deste capítulo). Nestas condições, para um tempo de 30 segundos de eluição, aproximadamente $3 \%$ do 
fosfato radioativo encontrava-se adsorvido na coluna.

Esta pequena quantidade retida na coluna só foi detectada pe 1o Geiger-Muller, visto que no método colorimétrico esse efeito não foi no tado devido provavelmente às baixas concentrações de fosfato utilizadas e à menor sensibilidade do sistema de detecção deste método espectrofotométrico. De qualquer forma, este possível efeito de memória em nada comprometeu os resultados analíticos, conforme pode ser observado na Figura 17.

Considerados estes aspectos, pode-se notar, pela Tabela 3 , a influência dos íons cloreto e nitrato na reação colorimétrica de fosfato. No ta-se pelos dados que, para uma concentração a $0,25 \mathrm{~N}$ em cloreto de sódio co mo carregador da amostra, os valores de absorbância dos padrões sofreram um decréscimo de aproximadamente $10 \%$ en comparação àqueles obtidos com carrega dor āgua. Esta variação provavelmente foi devida à interferência do 'íon cloreto no método colorimétrico. Para as soluções de nitrato de sódio é nitrato de amônio, esse efeito não foi notado. Desta forma, poder-se-ia optar pelas soluções de nitrato de sódio e nitrato de amônio, visto que essas soluções não provocaram nenhuma'interferência no método colorimétrico e também poderiam ser utilizadas como agentes eluentes em vista dos resultados obtidos anteriormente. Preferiu-se empregar nitrato de amônio pelas seguintes razões: o $\mathrm{pH}$ desta solução $0,25 \mathrm{~N}$ (em torno de 5,2) oferece boas condições de concentração e eluição do fosfato na coluna; com esta solução pode-se, futuramente, acoplar a técnica de troca iônica a detectores de emissão atômica para anālise de diversos ânions, uma vez que o íon sōdio, quando presente em altas concentrações (acima de 500 ppm), provoca grande interferência espectral na anālise dos outros elementos. 
Tabela 3 - Efeito das soluções carregadoras de amostra (eluente) na reação colorimétrica do fosfato. Os padrões de fosfato, preparados nos diferentes carregadores (dados expressos em unidades de absorbância).

\begin{tabular}{|c|c|c|c|c|}
\hline $\begin{array}{c}\text { Padrões } \mathrm{PO}_{4}^{3-} \\
(\mathrm{ppm})\end{array}$ & $\mathrm{H}_{2} \mathrm{O}$ & $\begin{array}{l}\mathrm{NaNO}_{3} \\
0,25 \mathrm{~N}\end{array}$ & $\begin{array}{l}\mathrm{NaCl} \\
0,25 \mathrm{~N}\end{array}$ & $\begin{array}{l}\mathrm{NH}_{4} \mathrm{NO}_{3} \\
0,25 \mathrm{~N}\end{array}$ \\
\hline 2,0 & 0,280 & 0,284 & 0,246 & 0,283 \\
\hline 1,0 & 0,138 & 0,142 & 0,119 & 0,140 \\
\hline 0,5 & 0,069 & 0,067 & 0,061 & 0,069 \\
\hline 0,2 & 0,035 & 0,035 & 0,027 & 0,035 \\
\hline 0,1 & 0,016 & 0,017 & 0,013 & 0,017 \\
\hline 0,05 & 0,008 & 0,008 & 0,006 & 0,008 \\
\hline & & & & \\
\hline
\end{tabular}


5.11. Influência de Alguns Ions na Retenção de Fosfato na Coluna de Resina

Conforme descrito no item 4.5.7, observou-se que as concentrações $100 \mathrm{ppm}$ de sulfato, $100 \mathrm{ppm}$ de nitrato e 50 ppm de cloreto não influenciavam na pré-concentração de fosfato na coluna de resina. Somente para as concentrações 100 e 300 ppm de cloreto foi observada tal influência. Nota-se, pela Figura 14, curva b, que os valores de absorbância relativos aos padrões sofreram um decréscimo de aproximadamente $5 \%$ quando em presença de 100 ppm de cloreto, em relação àqueles obtidos para as soluções contendo apenas fosfato (curva a). Já, em presença de 300 ppm de cloreto, este decréscimo chegou ao redor de $45 \%$ (curva c). Estas variações, provavelmente, foram devidas às quantidades dos diversos ânions que foram passados na coluna juntamente com o fosfato. Ou seja, para concentrações 50 ppm de cloreto e 100 ppm de nitrato e sulfato, que correspondem, respectivamente, a 1,41 eq $\mu \mathrm{g} / \mathrm{m} 1,1,61$ eq $\mu \mathrm{g} / \mathrm{m} 1$ e 1,04 eq $\mu \mathrm{g} / \mathrm{ml}$ destes ions, a retenção de fosfato não foi afetada. Quando foi aumentada a quantidade de cloreto para 2,82 eq $\mu \mathrm{g} / \mathrm{ml}$ (100 ppm), a retenção do fosfato foi prejudicada, sendo tão mais intenso o processo quanto maior a quantidade de cloreto. interessante considerar que nas situações $j a ́$ descritas, a resina se encontra va na forma de nitrato, onde, provavelmente, o cloreto competia com o fosfato na zona de troca. Substituindo-se o carregador nitrato por uma solução de cloreto de sódio de igual concentração $(0,25 \mathrm{~N})$, foi possível resolver o problema, uma vez que a coluna de resina, já saturada comcloreto, $\underline{\underline{f a}}$ voreceu o processo de troca dos íons fosfato. Est e resultado pode ser ob servado na Figura 15, onde a diferença entre as duas curvas foi devida à influência, já discutida, do íon cloreto no método colorimétrico. 


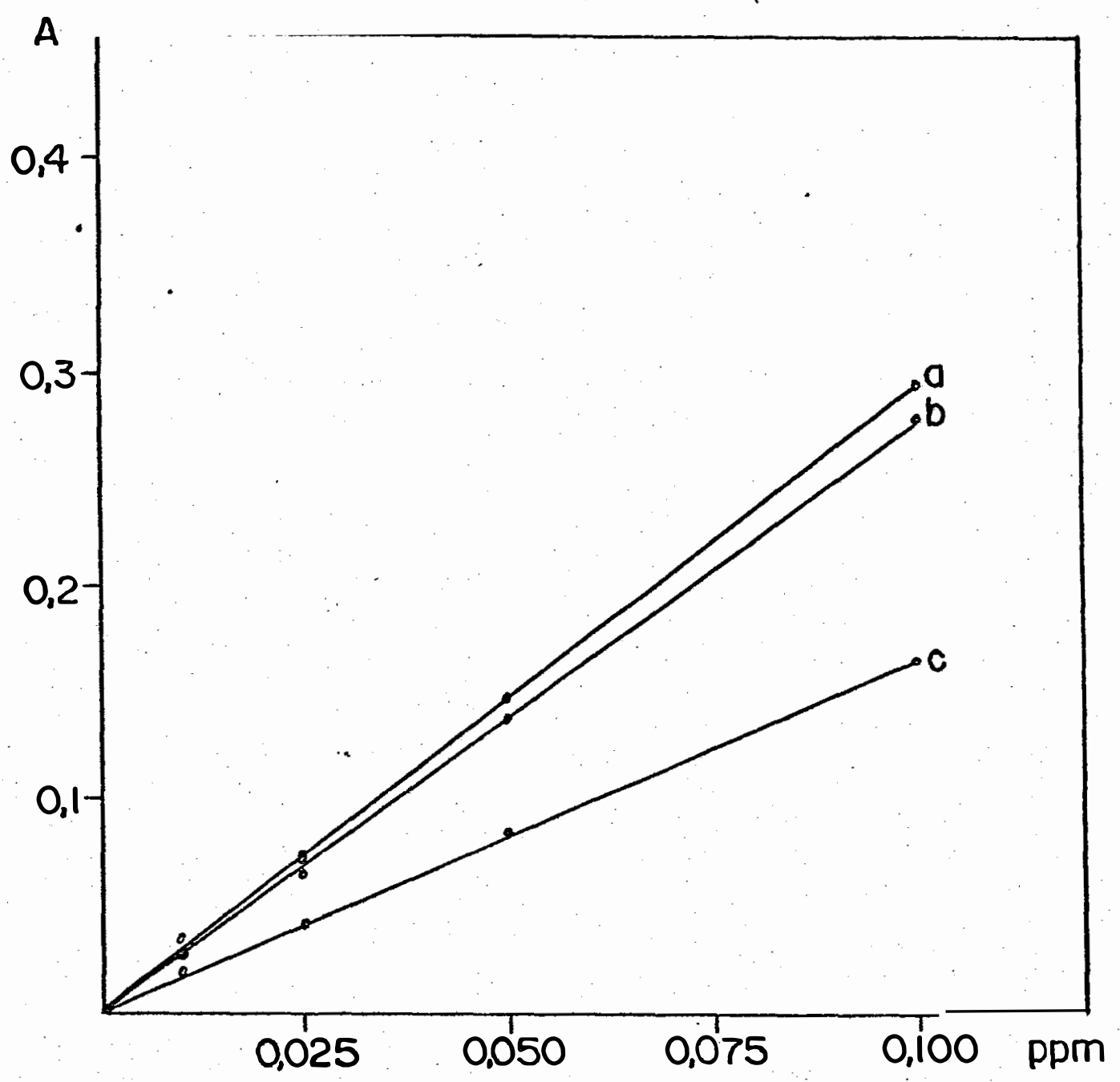

FIGURA 14 - Influência do íon cloreto na retenção de fosfato na coluna de resina (forma $\mathrm{NO}_{3}^{-}$).
a - curva padrão de fosfato (sem $\mathrm{Cl}^{-}$)
b - curva padrão de fosfato contendo $100 \mathrm{ppm} \mathrm{C1}^{-}$
c - curva padrão de fosfato contendo $300 \mathrm{ppm} \mathrm{Cl}^{-}$ 


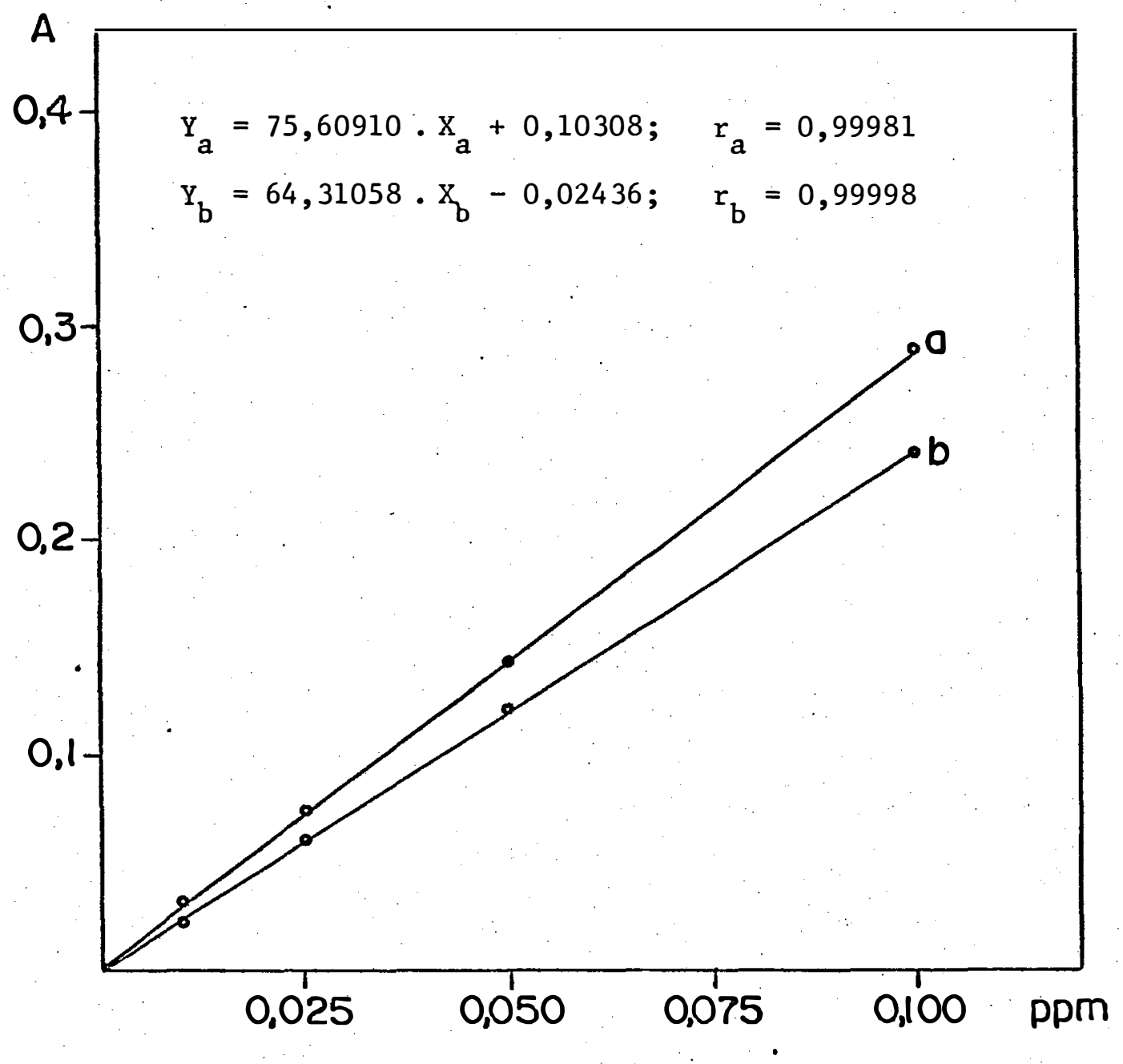

FIGURA 15 - Valores de absorbância de padrões de fosfato em ausência e pre sença de cloreto.

a - curva padrão de fosfato (resina na forma $\mathrm{NO}_{3}^{-}$)

b - curva padrão de fosfato contendo $300 \mathrm{ppm} \mathrm{de} \mathrm{Cl}^{-}$(resina na forma $\mathrm{Cl}^{-}$) 


\subsection{Efeito do Tempo de Pré-Concentração da Amostra}

Verificou-se, através do experimento descrito no item 4.5.8, a influência do tempo de pré-concentração da amostra na sensibilidade do mé todo. Observa-se, pelas curvas da Figura 16, o significativo aumento na absorbância do composto com o aumento do tempo de concentração da amostra injetada no sistema. Este resultado já era esperado, pois, à medida que são passados na resina volumes crescentes da mesma solução, maior é a quantidade de fosfato presente. Verificou-se também que, a partir do tempo de 90 segundos, houve uma perda de linearidade do sinal para todos os padrões de fosfato, sendo essa perda mais acentuada para o padrão de 0,1 ppm. Tal fato pode ser compreendido baseado em considerações descritas por SAMUELSON (1963), acerca do processo de adsorção. Inicialmente, a resina encontrase numa determinada forma (no nosso caso, na forma de nitrato). $\bar{A}$ medida que se inicia o processo de pré-concentração, os íons que entram (fosfato) movem-se através da coluna até atingirem a zona de troca. Nesta região existirá um equilíbrio entre os dois íons. Essa zona continua a mover-se através da coluna até atingir o limite de deslocamento (break-through), o que significa que íons fosfato podem ser detectados no efluente. Desta for ma, provavelmente, a partir de 90 segundos de pré concentração, uma certa quantidade de íons fosfato poderia ser encontrada na solução de saída, ocasionando a consequente perda de linearidade. Independente deste resultado, o tempo de pré-concentração de $60 \mathrm{~s}$ foi escolhido, pois a velocidade analítica do método deveria ser considerada. Em caso de se necessitar uma maior sensibil $\underline{i}$ dade, sem se preocupar com a velocidade analítica, os tempos de 90 ou 120 segundos poderão ser utilizados e, provavelmente poderão ser alcançadas curvas de padronização de forma linear, aumentando-se o tamanho da coluna. 


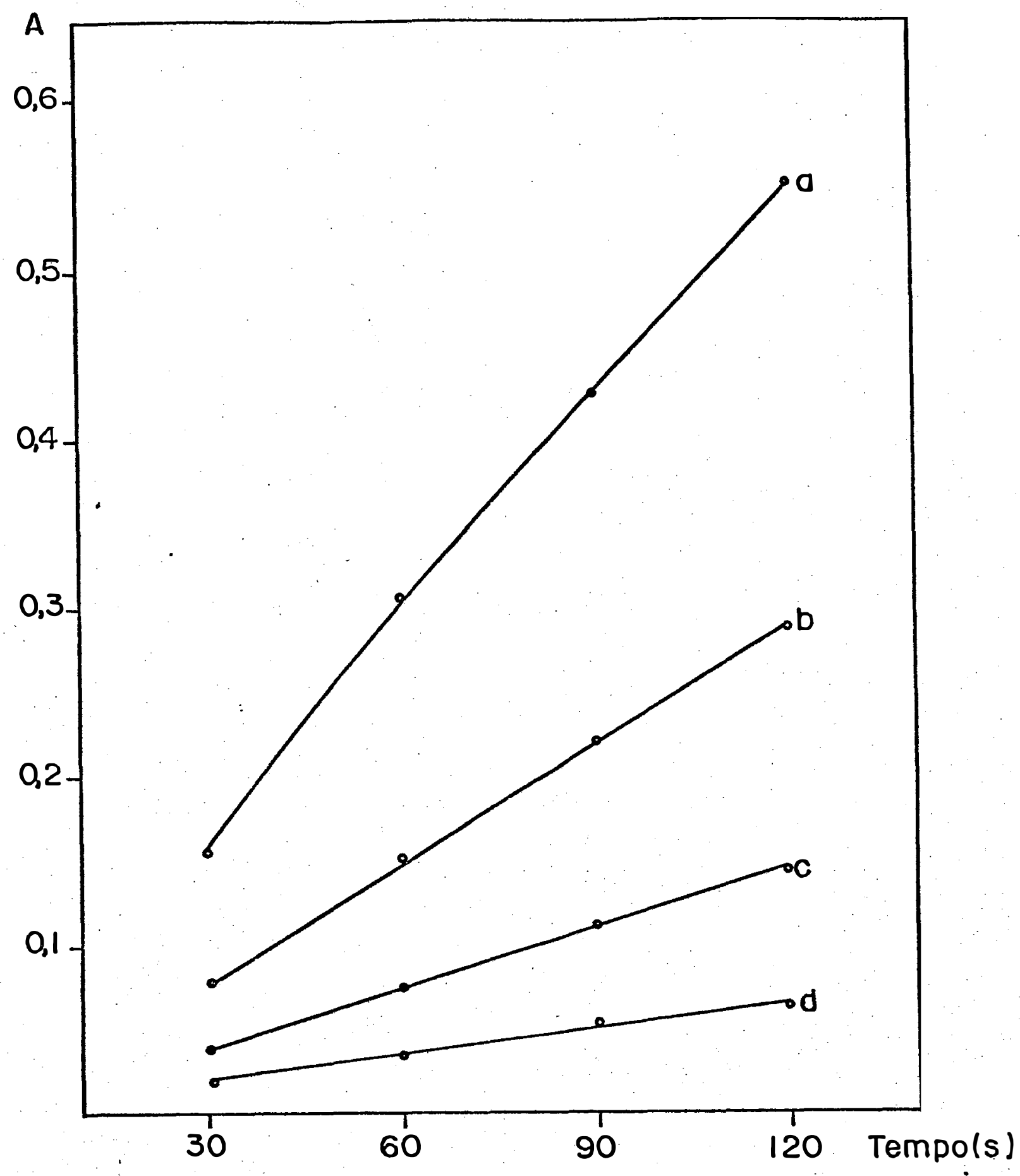

FIGURA 16 - Efeito do tempo de pré-concentração da amostra na coluna de resina.
a. 0,100 ppm fosfato
b - 0,050 ppm fosfato
c - 0,025 ppm fosfato
d - 0,010 ppm fosfato 


\subsection{Efeito do $\mathrm{pH}$ ou das Formas de Fosfato}

$$
0 \text { efeito do } \mathrm{pH} \text { ou das formas de fosfato na retenção e elui }
$$

ção deste íon na coluna de resina, foi verificado conforme procedimento des crito no item 4.5.9.

Como cita APHA/AWWA/WPCF (1975), o pH de amostras de águas naturais pode variar no intervalo de 4,0 a 9,0. Nestas condições, segundo DAY e UNDERWOOD (1974), as formas de fosfatọ encontradas são, predominantemente, $\mathrm{H}_{2} \mathrm{PO}_{4}^{-}$e $\mathrm{HPO}_{4}^{2-}$, respectivamente.

Os resultados encontrados mostraram que o $\mathrm{pH}$ e, consequentemente, as formas de fosfato existentes não influíram na retenção e eluição. Tal comportamento está coerente com as características da resina (Tabela 1), ou seja, na referida faixa de $\mathrm{pH}$ e para as quantidades de fosfato estudadas, a predóminância de qualquer daquelas formas não permitiu que fossem observa das modificações no comportamento da resina. 


\subsection{Caracterīsticas Analíticas}

\subsubsection{Exatidão}

Uma vez que não foi possível a obtenção de materiais de referência, ou seja, amostras de āgua com valores certificados da concentração de fosfato, nem o emprego de outro método para comparação dos resultados, a exatidão do método proposto foi avaliada através da técnica de padronização interna. A referida técnica consiste nạ adição de quantidade conhecida do elemento à amostra, num estāgio anterior ao procedimento analítico. (FRITZ e SCHENK, 1976; INTERNATIONAL UNION OF PURE AND APPLIED CHEMISTRY - IUPAC, 1979). Os resultados do teste de recuperação, usando desta técnica, são a presentados na Tabela 4 e revelaram uma porcentagem de recuperação média em torno de $98 \%$. A velocidade analítica do método proposto pode ser observada na Figura 17 e se apresenta em torno de 40 determinações por hora, na faixa de 0,005 a 0,100 ppm de fosfato.

\subsubsection{Precisão}

A precisão do método foi avaliada segundo o procedimento descrito em 4.5.10.2, utilizando amostras contendo, respectivamente, 0,022 e 0,064 ppm de fosfato, Desvios padrões relativos inferiores a $1 \%$ foram sempre calculados. 


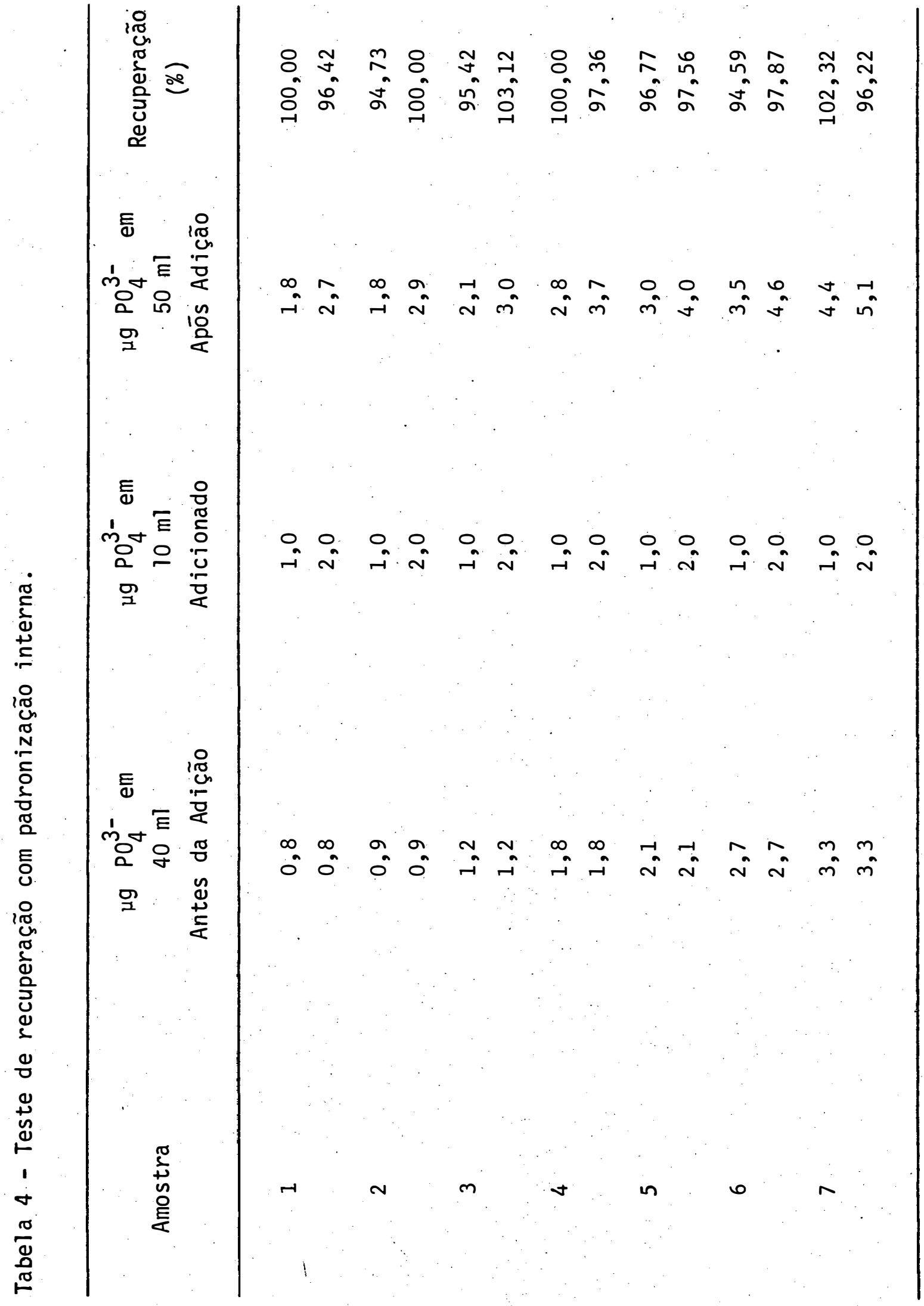




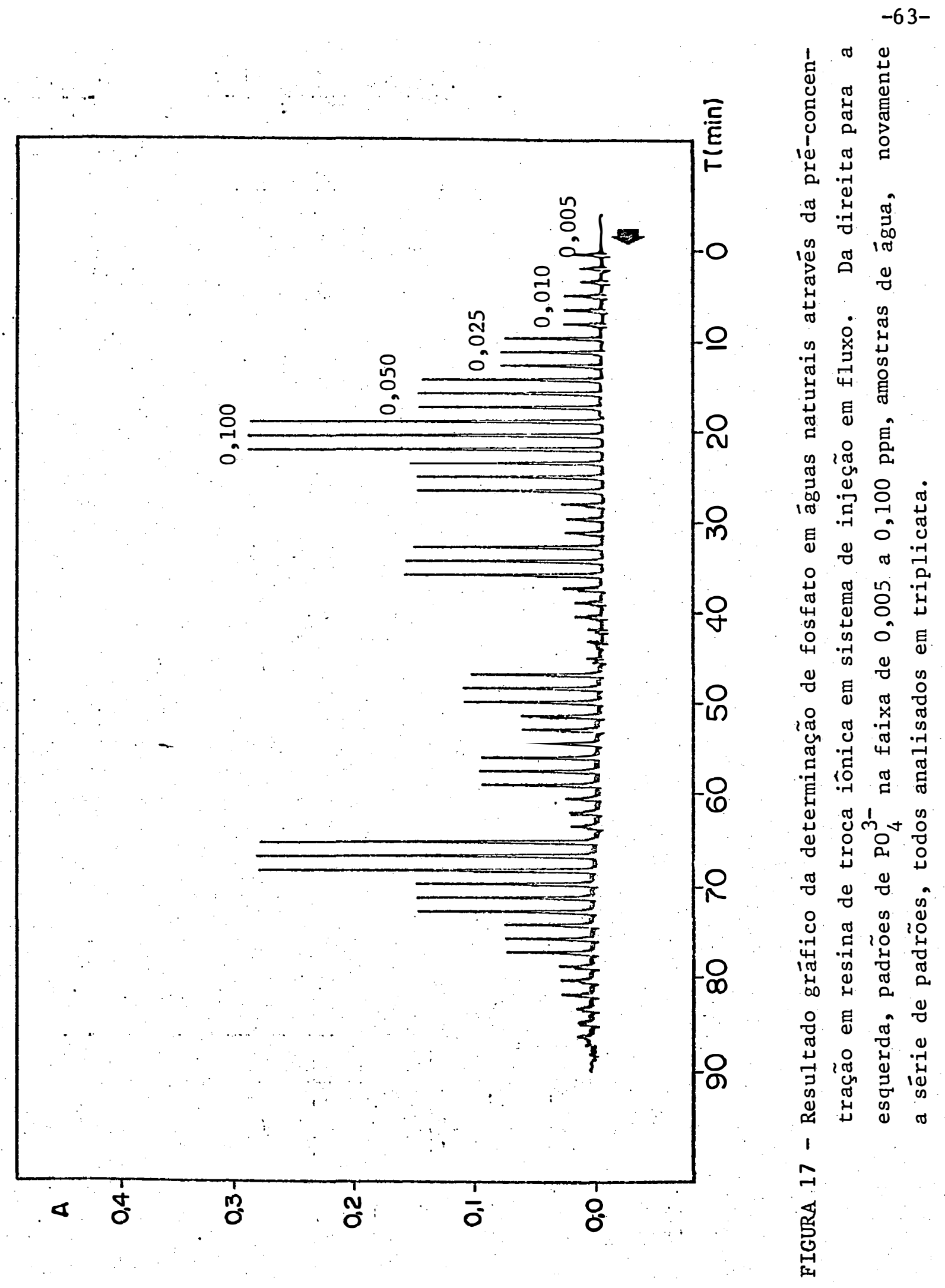




\section{CONCLUSODES}

a) 0 método do azul de molibdênio, em sistema de injeção em fluxo, empregando resina de troca iônica, pode ser utilizado para a determinação de baixas concentrações de fosfato em āguas naturais, apresentando vantagens em relação aos métodos convencionais manuais e automá ticos.

b) Estas vantagens estão, principalmente, relacionadas à ve locidade analítica, menor consumo de reagentes, a não utilização de solven tes orgânicos e acessōrios específicos, simplicidade operacional.

c) Determinação de baixas concentrações de fosfato (abaixo de 0,1 ppm), em águas naturais, podem ser feitas através do sistema de flu xos da Figura 4, com uma precisão superior a $99 \%$ e recuperação média em torno de $98 \%$.

d) Determinação de fosfato em amostras de āgua, com teores entre 0,1 e 2,0 ppm pode ser feita através do sistema de fluxos da. Figura 4, substituindo-se a coluna de resina por um "loop" de amostra de $500 \mu 1$. 
e) A velocidade analítica de aproximadamente 40 determinações por hora pode ser aumentada quando maiores teores de fosfato estiverem presentes nas amostras.

f) 0 limite de deteç̧ão em torno de 0,005 ppm de fosfato, po de ser aumentado pré-concentrando maiores volumes de amostra ou utilizando vazões de pré-concentração da amostra inferiores a $10 \mathrm{ml} / \mathrm{min}$.

g) Um tempo de 30 segundos foi suficiente para eluir pratica mente todo o fosfato retido na coluna, quando utilizou-se de uma vazão de e luição de $4 \mathrm{ml} / \mathrm{min}$ e concentração do eluente a $0,25 \mathrm{~N}$ em nitrato de amônio. Soluções de cloretos e sulfatos também podem ser empregadas como eluentes.

h) Não foram observadas influências de até 100 ppm de nitrato ou sulfato na retenção de fosfato pela coluna de resina.

i) Quando concentrações acima de $100 \mathrm{ppm}$ de cloreto estiverem presentes nas amostras, a troca da solução carregadora de amostra (nitrato de amônio $0,25 \mathrm{~N}$ ) por uma de cloreto de sódio na mesma concentração se faz necessário.

j) Variações no $\mathrm{pH}$, no intervalo de 4,0 a 9,0, não influenciaram na retenção ou eluição do fosfato pela coluna de resina. 


\section{LITERATURA CITADA}

ABBOT, D.C.; G.E. EMSDEN e J.R. HARRIS, 1963. A method for determining ortophosphate in water. Analyst, London, 88: 814-816.

ADAMSKI, J.M. e S.P. VILLARD, 1975. Application of the methylthymol blue sulphate method to water and wastewater analysis. Analytical Chemistry, Washington, . 47(7): 1191-1194.

APHA/AWWA/WPCF, 1975. Standard methods for the examination of water and waste-water. 14a. ed. New York. p. 466-470.

BARTON, C.J., 1948. Photometric analysis of phosphate rock. Analytical Chemistry, Washington, 20(11): 1068-1072.

BERGAMIN FILHO, H.; E.A.G. ZAGATTO; F.J. KRUG e B.F. REIS, 1978. Merging zones in flow injection analysis. Part 1. "Double proporcional injector and reagent consumption". Analytica Chimica Acta, Amsterdam, 101: 17-23.

BERGAMIN FILHO, H.; B.F. REIS; A.O. JACINTHO e E.A.G. ZAGATTO, 1980. Ion exchange in flow injection analysis. Determination of amonium ions at 
the $\mu \mathrm{g} .1^{-1}$ level in natural waters with pulsed Nessler reagent. Analytica Chimica Acta, Amsterdam, 117: 81-89.

BLANCHAR, R.W. e D. RIEGO, 1975. Phosphate determinations in water using anion exchange resin. Journal Environmental Quality, Madison, 4(1): 45-49.

BOLTZ, D.F., 1958. Colorimetric determination of nonmetals. New York, Interscience. p. 32-40.

DAY FR., R.A. e A.L. UNDERWOOD, 1974. Quantitative Analysis. 3. ed. Englewood Clifs, Prentice-Hall. p. 126-129.

DILTS, R.V., 1974. Analytical Chemistry: methods of separation. New York, D. Van Nostrand.

FLORENCE, T.M. e G.E. BATLEY, 1975. Removal of tracer metals from seawater by a chelating resin. Talanta, London, 22: 201-204.

FRITZ, J.S. e G.H. SCHENK, 1976. Quantitative Analytical Chemistry. Boston, A11yn and Bacom, 506 p.

GING, N.S., 1956. Extraction method for colorimetric determination of phosphorus in microgram quantities. Analytical Chemistry, Washington, 28: 1330-1333.

GRANDE, A.J. e J. BEUKENKAMP, 1956. Gradient elution chromatography of phosphates. Analytical Chemistry, Washington, 28(9): 1497-1498.

HANSEN, E.H. e J. RUZICKA, 1976. Flow injection analysis. Part VI. The determination of phosphate and chloride in blood serum by dialysis and sample dilution. Analytica Chimica Acta, Amsterdam, 87: 353-363.

HANSEN, E.H.; F.J. KRUG; A.K. GHOSE e J. RUZICKA, 1977. Rapid determination 
of nitrogen, phosphorus and potassium in fertilizers by flow injection analysis. Analyst, London, 102: 714-722.

HENRIKSEN, A., 1965. An automatic method for determining low-leve1 concentrations of phosphates in fresh and saline waters. Analyst, London, 90: 29-34.

HESLOP, R.B. e E.F. PEARSON, 1967. Liquid extraction of molybdophosphoric and molybdoarsenic acids: application to the determination of phosphorus in the presence of arsenic. Analytica Chimica Acta, Amsterdam, 39 : 209-221.

INTERNATIONAL UNION OF PURE AND APPLIED CHEMISTRY/Comission on spectrochemical and other optical procedures for analysis, 1978. Nomenclature, symbols, units and wage in spectrochemical analysis I, II, III. Spectrochimica Acta, 0xford, 338(6), p. 261.

JONES, P.G.W. A C.P. SPENCER, 1963. Comparison of several methods for determining inorganic phosphate in seawater. Journal of the Marine Biological Association of the United Kingdom, London, 43: 251-273.

KARLBERG, B. e S. THELANDER, 1978. Extraction based on the flow injection principle. Part I. Analytica Chimica Acta, Amsterdan, 98: 1-7.

KINGSTON, H.M.; I.L. BARNES; T.J. BRADY e T.C. RAINS, 1978. Separation of eight transition elements from alkali and alkaline earth elements in estuarine and seawater with chelating resin and their determination by graphite furnace atomic absorption spectrometry. Analytical Chemistry, Washington, $50(14)$ : 2064-2070. 
KLEIN, L., 1959. River pollution. I. Chemical analysis. London, Butterworths. p. 116-117.

KLINGHOFFER, 0.; J. RUZICKA e E.H. HANSEN, 1979. Flow injection analysis of traces of lead and cadmium by solvent extraction with dithizone. Talanta, London, 27: 169-175.

KOLLOFF, R.H., 1959. Analysis of commercial sodium tripolyphosphate by reverse flow ion exchange chromatography. ASTM Bulletin, Easton, 239: $74-80$.

KOLTHOFF, I.M. e P.J. ELVING, 1961. Treatise on analytical chemistry. New York, Interscience. v. 5, part II, p. 356-370.

KRAUS, K.A., 1957. Ion exchange. In: YOE, J.H. e H.J. KOCH JR. Trace analysis. New York, John Wiley. p. 34-101.

KRUG, F.J.; H. BERGAMIN FILHO; E.A.G. ZAGATTO e S. STORGAARD JøRGENSEN, 1977. Rapid determination of sulphate in natural waters and plant digests by continuous flow injection turbidimetry. Analyst, London, 102: 503-508.

KRUG, F.J.; J. MORTATTI; L.C.R. PESSENDA; E.A.G. ZAGATTO e H. BERGAMIN FILHO, 1981. Flow injection spectrophotometric determination of boron in plant material with azomethine-H. Analytica Chimica Acta,Amsterdam, 125: 29-35.

LINDENBAUM, S.; T.V. PETERS FR. e Wm. RIEMAN III, 1954. Analysis of mixtures of the condensed phosphates by ion-exchange chromatography. Analytica Chimica Acta, Amsterdan, 11: 531-537.

MARCZENKO, Z., 1976. Spectrophotometric Determination of EZements. Chichester, E11is Horwood. p. 422-429. 
MASON, B.H., 1971. Principios de Geoquimica. Trad. de R.R. Franco. São Paulo, Polígono/USP. p. 246-247.

MEDEIROS, J.X., 1979. Determinação de molibdênio em material de plantas por extração com solventes em fluxo contínuo. Piracicaba, ESALQ/USP. 100 p. (Dissertação de Mestrado).

MORTATTI, J., 1981. Determinação espectrofotométrica de baixos níveis de chumbo em águas naturais e extratos vegetais, usando extração com so1ventes em sistema de injeção em fluxo. Piracicaba, ESALQ/USP. 56 p. (Dissertação de Mestrado).

MURPHY, J. e J.P. RILEY, 1962. A modified single solution method for the determination of phosphate in natural waters. Analytica Chimica Acta, Ams terdan, 27: 31-36.

OHLWEILER, 0.A., 1974. Quimica Analitica Quantitativa. Rio de Janeiro, Livros Técnicos e Científicos. Brasília, INL, v. 1. p. 233-238.

OLTMAN, R.E., 1967. Reconnaissance investigation of the discharge and water quality of the Amazon, 1967. In: Simpósio sobre a Biota Amazônica, Belém, 6-11 junho, 1966. Atas. Rio de Janeiro, Conselho Nacional de Pesquisas. v. 3, p. 165-185.

PAKALNS, P., 1970. Spectrophotometric determination of phosphorus in aluminium, copper and nickel allays, and white metals. Analytica Chimica Acta, Amsterdan, 51: 497-501.

PAUL, J., 1966. Simultaneous determination of phosphorus, arsenic and germanium and the separation of silicon and arsenic by solvent extraction. 
Analytica Chimica Acta, Amsterdan, 35: 200-205.

PETERS, T.V. e Wm. RIEMAN III, 1956. Analysis of mixtures of the condensed phosphates by ion-exchange chromatography. Analytica Chimica Acta, Amsterdan, 121: 131-135.

POLLARD, F.H.; D.E. ROGERS; M.T. ROTHWELL e G. NICKLESS, 1962. Séparation of hypophosphite, phosphite and phosphate by anion-exchange chromatography. Journal of Chromatography, Amsterdan, 9: 227-230.

RANGER, C., 1981. Flow injection analysis, principles, techniques, applications designs. Analytical Chemistry, Washington, 53(1): 20a-33a.

REIS, B.F.; A.0. JACINTHO; J. MORTATTI; F.J. KRUG; E.A.G. ZAGATTO; H. BERGAMIN FILHO e L.C.R. PESSENDA, 1981. Zone-sampling processes in flow injection analysis. Analytica Chimica Acta, Amsterdan, 123: 221-228.

ROBBINS, C.W.; D.L. CARTER e D.W. JAMES, 1973. Potentiometric titration of sulphate in water and soil extracts using a lead-mercury amalgam indicator electrode. Soil Science Society American Proceedings, Madison, 37: 212215.

RUZICKA, J. e E.H. HANSEN, 1975. The concept of a new, simple, ultrafast continuous flow analyser. Part I. Analytica Chimica Acta, Amsterdan, 78: 145-157.

RUZICKA, J. e J.W.B. STEWART, 1975. Flow injection analysis. Part II. U1trafast determination of phosphorus in plant material by continuous flow spectrophotometry. Analytica Chimica Acta, Amsterdan, 79: 79-81.

RUZICKA, J: e E.H. HANSEN, 1978. Flow injection analysis. Part X. Theory, 
techniques and trends. Analytica Chimica Acta, Amsterdan, 99(1): 37-97.

RUZICKA, J. e E.H. HANSEN, 1981. Flow injection analysis. New York, John Wiley-Interscience. p. 133-134.

SAMUELSON, 0., 1963. Ion exchange separation in analytical chemistry. New York, John Wiley, p. 70-94.

SHEN, C.Y. e D.R. DYROFF, 1964. Determination of phosphate in presence of silicates by molybdenum blue method. Analytical Chemistry, Washington, $34(8): 1367-1374$.

SPANGLER, W.G.; D.E. HOWES e J.A. KISH, 1950. Analysis of commercial triphosphite. ASTM BuZZetin, Easton, 228: 61-65.

STEVENS, K., 1963. Determination of low phosphate concentration in lake and marine waters. Limnology and Oceanography, Baltimore, 8: 361-362.

TAYLOR, E.W., 1958. The examination of waters and water supplies: thresh, beale e suckling. 7a. ed. Boston, Little Brown, p. 142-144.

TECHNICON INDUSTRIAL SYSTEMS, 1973. Ortophosphate in water and wastewaterIndustrial method nọ 94-70w, Tamytown (Technicon Autoanalyzer II).

THEABSTON, H.M. e W.R. BANDI, 1966. Spectrophotometric determination of trace amounts of phosphorus in high alloy steel. Analytical Chemistry, Washington, 38(12): 1764-1767.

TYLER, L.P. e A.F. BILES, 1970. Complete automation of low-level total phosphorus analysis in water. Technicon International Congress. New York. 
WOLF, W.R. e K.K. STEWART, 1979. Automated multiple flow injection analysis for flame atomic absorption spectrometry. Analytical Chemistry, Washington, 51(8): 1201-1205.

YAMAGAMI, E.; S. TATEISHI e A. HASHIMOTO, 1980. Application of a chelating resin to the determination of trace amounts of mercury in natural waters. Analyst, London, 105: 491-496. 